\title{
Modeling the Interaction between $\beta$-Amyloid Aggregates and Choline Acetyltransferase Activity and Its Relation with Cholinergic Dysfunction through Two-Enzyme/Two-Compartment Model
}

\author{
Hedia Fgaier, ${ }^{1}$ Ibrahim H. I. Mustafa, ${ }^{2,3}$ Asmaa A. R. Awad, ${ }^{3}$ and Ali Elkamel ${ }^{3}$ \\ ${ }^{1}$ Department of Mathematics and Statistics, University of Guelph, Guelph, ON, Canada N1G 2W1 \\ ${ }^{2}$ Biomedical Engineering Department, Faculty of Engineering at Helwan, Helwan University, Helwan, Cairo 11792, Egypt \\ ${ }^{3}$ Chemical Engineering Department, University of Waterloo, Waterloo, ON, Canada N2L 3G1
}

Correspondence should be addressed to Ibrahim H. I. Mustafa; ibm_hassan@yahoo.com and Ali Elkamel; aelkamel@uwaterloo.ca

Received 25 March 2015; Accepted 14 July 2015

Academic Editor: David A. Winkler

Copyright (C) 2015 Hedia Fgaier et al. This is an open access article distributed under the Creative Commons Attribution License, which permits unrestricted use, distribution, and reproduction in any medium, provided the original work is properly cited.

\begin{abstract}
The effect of $\beta$-amyloid aggregates on activity of choline acetyltransferase (ChAT) which is responsible for synthesizing acetylcholine $(\mathrm{ACh})$ in human brain is investigated through the two-enzyme/two-compartment $(2 \mathrm{E} 2 \mathrm{C})$ model where the presynaptic neuron is considered as compartment 1 while both the synaptic cleft and the postsynaptic neuron are considered as compartment 2 through suggesting three different kinetic mechanisms for the inhibition effect. It is found that the incorporation of ChAT inhibition by $\beta$-amyloid aggregates into the $2 \mathrm{E} 2 \mathrm{C}$ model is able to yield dynamic solutions for concentrations of generated $\beta$-amyloid, $\mathrm{ACh}$, choline, acetate, and $\mathrm{pH}$ in addition to the rates of ACh synthesis and ACh hydrolysis in compartments 1 and 2. It is observed that ChAT activity needs a high concentration of $\beta$-amyloid aggregates production rate. It is found that ChAT activity is reduced significantly when neurons are exposed to high levels of $\beta$-amyloid aggregates leading to reduction in levels of ACh which is one of the most significant physiological symptoms of AD. Furthermore, the system of ACh neurocycle is dominated by the oscillatory behavior when ChAT enzyme is completely inhibited by $\beta$-amyloid. It is observed that the direct inactivation of ChAT by $\beta$-amyloid aggregates may be a probable mechanism contributing to the development of AD.
\end{abstract}

\section{Introduction}

Choline acetyltransferase (ChAT) is a single-strand globular protein and catalyzes biosynthesis reaction of acetylcholine (ACh) neurotransmitter [1]. It was discovered in rabbit brain by Nachmansohn and Machado in 1943 [2]. ChAT is present in two forms in nerve terminal: (i) nonionic membranebound and (ii) soluble form. ChAT synthesis occurs in the rough endoplasmic reticulum in cholinergic neuron cells. Then, it is transferred to axon terminal for ACh synthesis via rapid and slow axoplasmic flow [3]. ChAT plays an essential role in cholinergic neuron cells and nonneuron cells. In neuron cells ChAT expression is a special marker for cholinergic system improvement during brain growth and development where ChAT is involved in activation of multiple neuropsychic functions such as memory, cognition, sleep, learning, and movement [4]. Therefore, any disturbance in ChAT levels inside neuron cells could generate serious negative consequences. For example, (i) downregulation of ChAT activity causes serious cholinergic disease such as dementia, schizophrenia, and Huntington's disease [5-7], (ii) ChAT abnormalities in the brain could lead to sudden death in infants [3], and (iii) ChAT inhibition leads to generation of Alzheimer's disease because ChAT is the enzyme that is responsible for ACh synthesis. Therefore, ChAT inactivation results in a decline of ACh levels in brain. Decreasing ACh concentration is the most common early stage features of AD. However, in nonneuron cells ACh generated by ChAT catalytic effect is secreted in extracellular space. ACh in extracellular space is necessary for maintaining homeostasis of cells and for modulating many of the essential cell functions such as cell division, mitosis, cytoskeleton 


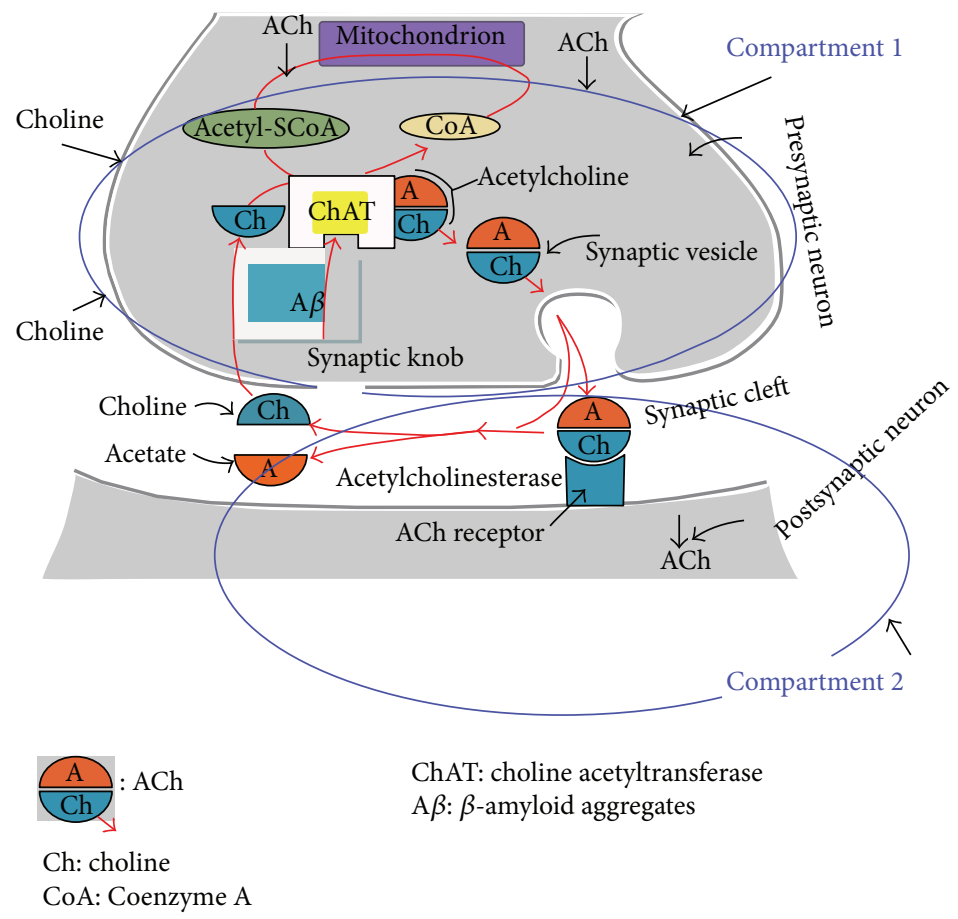

FIGURE 1: Schematic representation of ChAT catalytic role in ACh synthesis: two-enzyme/two-compartment $(2 \mathrm{E} 2 \mathrm{C})$ model $[5,6]$.

organization, interactions between cells, and maintaining the immune functions [4]. As shown in Figure 1 ChAT is concentrated in the presynaptic neuron of the cholinergic neuron because of its necessity for ACh synthesis $[6,8]$ where ChAT catalyzes the reaction between choline (taken from extra cellular fluid by high-affinity transporter carrier) and acetyl-CoA (produced during glucose metabolism in mitochondria) to produce ACh; ChAT facilitates the transfer of acetyl moiety from acetyl-CoA to choline to give ACh and enzyme-CoA as indicated in

$$
\begin{aligned}
& \left(\mathrm{CH}_{3}\right)_{3} \underset{\text { Choline }}{\stackrel{+}{\mathrm{N} C H} \mathrm{H}_{2} \mathrm{CH}_{2} \mathrm{OH}}+\underset{\text { Acetyl coenzyme A }}{\mathrm{CH}_{3} \mathrm{COSCoA}} \\
& \stackrel{\mathrm{ChAT}}{\longleftrightarrow}\left(\mathrm{CH}_{3}\right)_{3} \stackrel{+}{\mathrm{N} C \mathrm{CH}_{2} \mathrm{CH}_{2} \mathrm{OCOCH}_{3}+\mathrm{CoASH}}
\end{aligned}
$$

There are various factors that could negatively affect ChAT activity such as excitatory amino acids, reactive oxygen species, and $\beta$-amyloid aggregates. The most serious defective factor is $\beta$-amyloid aggregates [9]. Incubation of nanomolar concentration of $\beta$-amyloid aggregates with $50 \%$ cultured cholinergic neurons caused complete ChAT inhibition [10]. ChAT inhibition by $\beta$-amyloid aggregates induces several cholinergic problems such as memory dysfunction, neuron impairment, and cognition declining. Since ChAT is an important indicator for health of cholinergic neurons and plays a necessary role for activating multiple neuropsychic functions, many researches focused on ChAT investigation such as Mustafa et al. [5, 6], Nunes-Tavares et al. [11], and Waser et al. [12].

The main goal of this work is to investigate the effect of wide range of concentrations of $\beta$-amyloid aggregates as inhibitor on ChAT activity in brain tissues and the consequences on the cholinergic neurocycle behavior such as concentrations of ACh, choline levels, acetate levels, and the rate of $\mathrm{ACh}$ synthesis and ACh hydrolysis in compartment 1 and compartment 2 , respectively. In this study three different kinetic mechanisms describing the interaction between $\beta$ amyloid aggregates and ChAT activity are proposed and the results of each mechanism are compared to each other in order to understand how $\beta$-amyloid aggregates could affect ChAT activity. The rate of ACh synthesis catalyzed by ChAT and affected by $\beta$-amyloid inhibitor and derived from each kinetic mechanism is incorporated into the two-enzyme/twocompartment model presented by Mustafa et al. $[5,6]$ to account for the effect of $\beta$-amyloid aggregates.

\section{Formulation of Interaction between $\beta$ - Amyloid Aggregates and ChAT Kinetics through 2E2C Model}

The ACh neurocycle is shown in Figure 1 where the presynaptic neuron represents the plant for ACh synthesis and contains the enzyme ChAT, choline, acetyl-CoA, ACh, and $\beta$-amyloid aggregates $(\mathrm{A} \beta)$. The presynaptic neuron is considered compartment 1 while both synaptic cleft and postsynaptic neuron represent compartment 2 . It is observed that choline is the only component produced from the hydrolysis which is recycled to compartment 1 and reused for ACh synthesis [5]. Tucek [13] showed that both ACh and acetyl$\mathrm{CoA}$ are synthesized in compartment 1 . Figure 2 shows a simple form of the feedback model of ACh cholinergic neurocycle shown in Figure 1. Every compartment is considered 


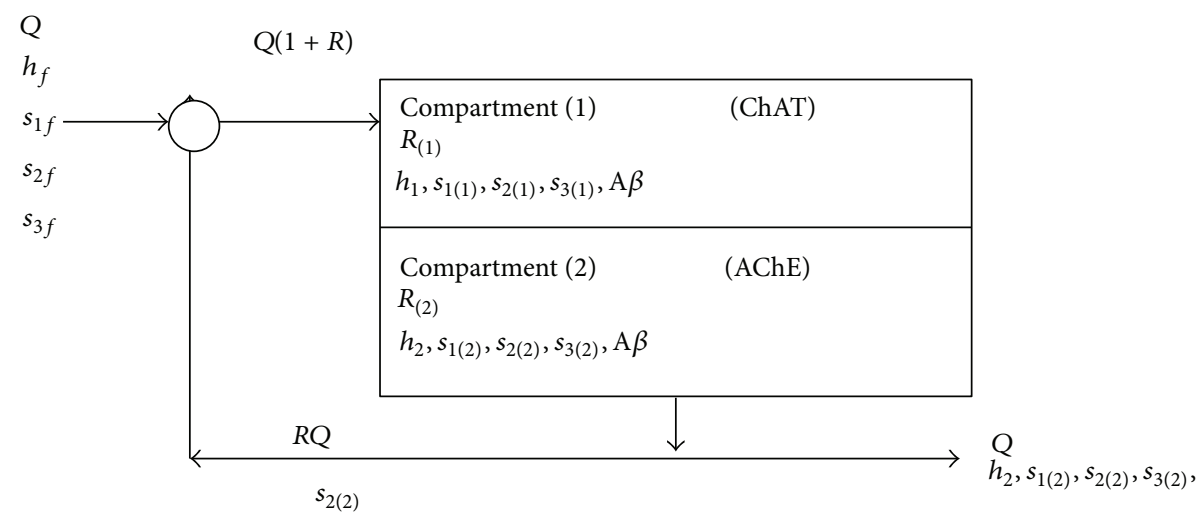

FIGURE 2: Schematic representation for two-enzyme/two-compartment model.

a constant volume and isothermal continuous stirred tank reactor (CSTR) with a constant flow rate and constant recycle ratio. Also, the two compartments are separated by a permeable membrane. $\beta$-amyloid aggregates interact with ChAT inside compartment 1 . Nunes-Tavares et al. [10] reported that there is a strong relation between $\beta$-amyloid peptides and cholinergic dysfunction which is one of the main symptoms of Alzheimer's disease (AD). Furthermore, $\beta$-amyloid could inhibit the activity of the enzyme ChAT leading to reduction in the levels of ACh and memory impairment [10]. ChAT activity could be completely reduced significantly with $\beta$ amyloid.

2.1. Model Assumptions. All assumptions made for investigating the effect of $\beta$-amyloid aggregates compatible with literature such as those cited by Mustafa et al. $[5,6]$ and Mustafa et al. [14, 15] are considered in this work. More justifications and assumptions are clarified below:

(1) The presynaptic of cholinergic nerve terminal is described by compartment 1 . Inside this compartment $\mathrm{ACh}$ is synthesized by the reaction of choline and acetyl-CoA in the presence of catalytic effect of ChAT enzyme.

(2) Postsynaptic cleft of neurons together with synaptic cleft are considered as compartment two. Both postsynaptic and synaptic clefts are unified to be in one compartment instead of two or three because both of them are harmonized and are interactive and also to simplify the calculations in solving the model particularly when the dimensionality is too high.

(3) Both compartments are assumed to be divided with a permeable membrane.

(4) The internal masses transfers in compartment one between synaptic vesicles and cytoplasm and in compartment two between ACh and postsynaptic receptors are neglected because every compartment is assumed to be homogenous.

(5) All matters in the presynaptic neuron are transported to the postsynaptic cleft via passive diffusion where all concentrations in compartment 1 should be higher than that in compartment 2; however, choline uptake from the postsynaptic cleft to the presynaptic neurons is performed by facilitated diffusion via high-affinity choline uptake transporters.

(6) It is observed that concentrations of all state variables in compartment two are the average of concentrations in postsynaptic and synaptic cleft.

(7) Temperature is considered constant where the system is assumed to be isothermal and there is no effect for any temperate changes on the system.

(8) Transport of $\beta$-amyloid aggregates from compartment 1 to compartment 2 is neglected. To justify, it is noted that transport of $\beta$-amyloid aggregates from compartment 1 to compartment 2 is by passive diffusion and the transport rate is extremely lower than that from the cytoplasm to compartment 1 . The latter transport (from cytoplasm to compartment 1) addresses the blood brain barriers according to saturable mechanism such as Monod and MichaelisMenten kinetics [16-18].

(9) The initial concentration of $\beta$-amyloid aggregates is assumed to be zero.

(10) Feed stream rate to compartment one and outlet flow from compartment two are considered to be constant with a value of $q\left(\mathrm{~m}^{3} / \mathrm{sec}\right)$.

2.2. Competitive Inhibition of ChAT in Two-Enzyme/TwoCompartment Model. ChAT and AChE are the two cholinergic enzymes considered in the $2 \mathrm{E} 2 \mathrm{C}$ model. ChAT is responsible for synthesis of $\mathrm{ACh}$ in compartment 1 of the 2E2C model, while AChE catalyzes the degradation of ACh in compartment 2. It is found that incorporation of $\beta$ amyloid aggregates into rat brains in vivo [19] and at nanoto picomolar concentrations into SN56 cell line in vitro [20] shows significantly a decrease in ChAT activity and ACh production. However, detection of change in AChE activity was readily observed and reported [21]. This finding suggests that $\beta$-amyloid aggregates may act as a general modulator of ChAT enzyme activity leading to a reduction in $\mathrm{ACh}$ synthesis [22]. 


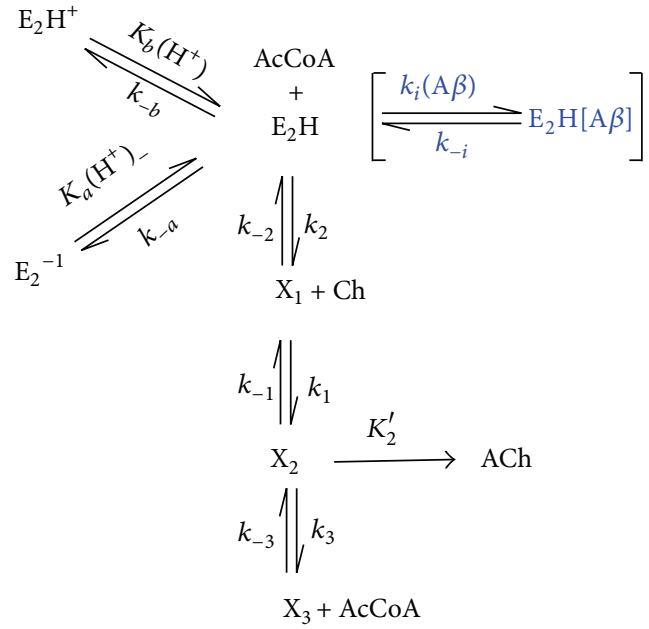

(a)

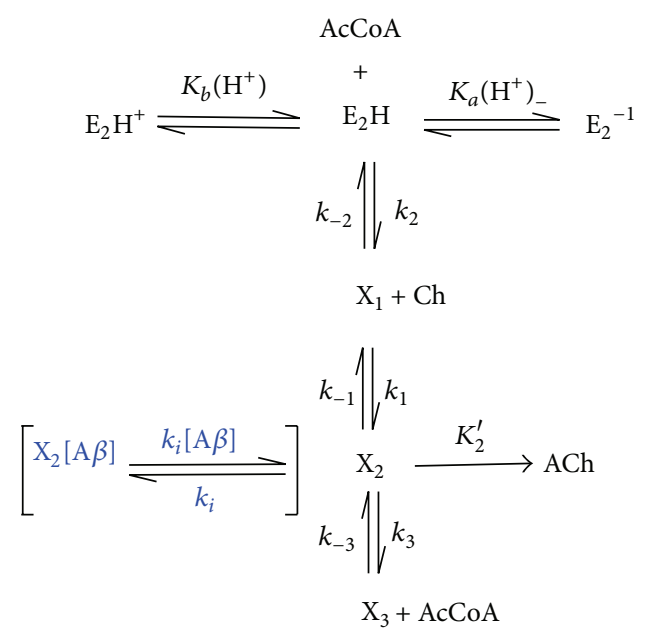

(b)

FIGURE 3: Possible competitive inhibition mechanisms for $\beta$-amyloid ([A $\beta]$ ) during pH-dependent ChAT synthesis of ACh (areas of inhibition are displayed in square brackets). The reaction route occurs in the vertical direction. $\mathrm{E}_{2} \mathrm{H}$ is the active form of the enzyme; $\mathrm{E}_{2} \mathrm{H}^{+}$ and $\mathrm{E}_{2}{ }^{-1}$ are the protonated and deprotonated inactive forms. $\mathrm{X}_{1}, \mathrm{X}_{2}$, and $\mathrm{X}_{3}$ are enzyme intermediate complexes. (a) $\beta$-amyloid competitively binds to active enzyme complex $\mathrm{E}_{2} \mathrm{H}$; (b) $\beta$-amyloid competitively binds to enzyme intermediate $\mathrm{X}_{2}$.

The exact mechanisms of ChAT modulation by $\beta$ amyloid aggregates are still currently unknown. It is possible that $\beta$-amyloid aggregates may directly inhibit ChAT activity by competitively binding to active sites or perhaps limit the activity of secondary proteins responsible for ChAT synthesis and regulation [23]. Since level of intracellular ChAT is generally maintained at a concentration much higher than that of the reactants for ACh production [24], modification of the $2 \mathrm{E} 2 \mathrm{C}$ model to incorporate inhibition of ChAT activity is required to understand the mechanisms of the interaction between ChAT and $\beta$-amyloid aggregates.

To examine the phenomenon of ChAT activity inhibition by $\beta$-amyloid aggregates in a simpler model, $\beta$-amyloid aggregate is considered to act directly as a competitive inhibitor of ChAT enzyme. Figure 3 illustrates a modified version of $\mathrm{pH}$-dependent enzyme synthesis reaction model used in the two-enzyme/two-compartment model. The modification (represented in square brackets) takes into account two possible pathways in which $\beta$-amyloid may bind competitively to intermediate complexes, thereby inhibiting their ability to progress to the main reaction direction (in the vertical pathway) towards $\mathrm{ACh}$ synthesis. In such case $\beta$ amyloid aggregates $(\mathrm{A} \beta)$ may bind directly to the active form of the enzyme $\mathrm{E}_{2} \mathrm{H}$ to generate the inactive $\mathrm{E}_{2} \mathrm{H}[\mathrm{A} \beta]$ complex (Figure 3(a)), thus limiting the availability of active enzymes to carry out ACh synthesis and decrease net enzyme activity. Similarly, it is also possible that $\beta$-amyloid may bind to the enzyme intermediate complex $\mathrm{X}_{2}$, thereby preventing $\mathrm{ACh}$ release from the complex (Figure 3(b)).

$\beta$-amyloid aggregates combine with ACh molecules in the presynaptic neuron (compartment 1) to form complexes which are unable to play the same role of ACh [23]. Therefore, the rate of decline in $\mathrm{ACh}$ is sensitive to the rate of generation of $\beta$-amyloid aggregates. To describe the relevant complex processes mathematically, the following ordinary differential equation is proposed to account for the reduction of $\mathrm{ACh}$ production in compartment $1\left(s_{1(1)}\right)$ due to the interaction with $\beta$-amyloid aggregates:

$$
\frac{d s_{1(1)}}{d T}=-K_{b A 1} s_{1(1)} \mathrm{A} \beta .
$$

It is assumed that the rate of $\mathrm{ACh}$ reduction is proportional to the concentration of $\beta$-amyloid $(\mathrm{A} \beta)$ aggregates and $\mathrm{ACh}$ in compartment 1 where $K_{b A 1}$ is constant. In addition, the sophisticated mathematical model is developed to investigate the interaction between $\beta$-amyloid aggregates and ChAT. The model takes into consideration generation and clearance of $\mathrm{A} \beta$ aggregates $[25,26]$. It is assumed that the level $\mathrm{A} \beta$ is kept via the balancing of a zero-order generation rate $\left(K_{L 2}\right)$ and first-order clearance processes $\left(K_{L 3} s_{1(1)}+K_{L 4} \mathrm{~A} \beta\right)$. The accumulation of $\mathrm{A} \beta$ is described by

$$
\frac{d \mathrm{~A} \beta}{d T}=K_{L 2}-K_{L 3} s_{1(1)}-K_{L 4} \mathrm{~A} \beta
$$

where the term $\left(K_{L 2}\right)$ describes the generation of $\mathrm{A} \beta$ aggregates from amyloid precursor protein, the term $\left(-K_{L 3} s_{1(1)}\right)$ describes the impact of ACh levels in the presynaptic neuron on the rate of formation of $\mathrm{A} \beta$ aggregates $[27,28]$ and the term $\left(-K_{L 4} \mathrm{~A} \beta\right)$ represents the reduction in $\mathrm{A} \beta$ aggregates levels due to the enzymatic hydrolysis and diffusion in the neuronal membranes [28].

The numerical derivation of the ChAT rate equation for the modified $\mathrm{pH}$-dependent $\mathrm{ACh}$ synthesis with competitive inhibition of $\beta$-amyloid is shown in Sections 3, 4, and 5. Equations (1) and (2) in addition the new ChAT rate equations $\left(r_{1}\right)$ derived from each kinetic mechanism are incorporated into the model built by Mustafa et al. $[5,6]$ to give our model as shown in Table 1. 


\section{Kinetic Mechanism 1: Competitive Inhibition of $\mathbf{A} \beta$ with All Species Activated Enzyme Complex $\mathrm{E}_{2} \mathrm{H}$}

3.1. Formulation of Kinetic Mechanism 1. The synthesis rate for competitive inhibition of $\mathrm{A} \beta$ aggregates with activated enzyme complex $\mathrm{E}_{2} \mathrm{H}$ can be derived as follows.

$\mathrm{X}_{1}$ and $\mathrm{X}_{2}$ are related to each other through the following equation:

$$
\begin{aligned}
\mathrm{X}_{1}(\mathrm{Ch}) k_{1} & =\mathrm{X}_{2} k_{-1} \\
\text { or } \mathrm{X}_{1} & =\frac{K_{1}}{\mathrm{Ch}} \mathrm{X}_{2},
\end{aligned}
$$

where $K_{1}=k_{-1} / k_{1}$

By the assumption of rapid equilibrium, $\mathrm{E}_{2} \mathrm{H}$ and $\mathrm{X}_{1}$ can be related by

$$
\begin{aligned}
k_{2}(\mathrm{AcCoA}) \mathrm{E}_{2} \mathrm{H} & =k_{-2} \mathrm{X}_{1} \\
\text { or } \mathrm{E}_{2} \mathrm{H} & =\frac{K_{1} K_{2}}{(\mathrm{AcCoA})(\mathrm{Ch})} \mathrm{X}_{2},
\end{aligned}
$$

where $K_{2}=k_{-2} / k_{2}$.

By rapid equilibrium assumption, $\mathrm{E}_{2} \mathrm{H}[\mathrm{A} \beta]$ complex can be expressed as

$$
\begin{aligned}
k_{i} \mathrm{E}_{2} \mathrm{H}(\mathrm{A} \beta) & =k_{-i} \mathrm{E}_{2} \mathrm{H}[\mathrm{A} \beta] \\
\text { or } \mathrm{E}_{2} \mathrm{H}[\mathrm{A} \beta] & =K_{i}(\mathrm{~A} \beta)\left(\mathrm{E}_{2} \mathrm{H}\right),
\end{aligned}
$$

where $K_{i}=k_{i} / k_{-i}$.
From the ionization of $\mathrm{E}_{2} \mathrm{H}$,

$$
\begin{aligned}
\mathrm{E}_{2} \mathrm{H}\left(\mathrm{H}^{+}\right) k_{-b} & =\mathrm{E}_{2} \mathrm{H}^{+} k_{b} \\
& \text { or } \mathrm{E}_{2} \mathrm{H}^{+}=\frac{\left(\mathrm{E}_{2} \mathrm{H}\right)\left(\mathrm{H}^{+}\right)}{K_{b}} .
\end{aligned}
$$

From the deionization of $\mathrm{E}_{2} \mathrm{H}$,

$$
\begin{aligned}
\mathrm{E}_{2}^{-}\left(\mathrm{H}^{+}\right) k_{a} & =\mathrm{E}_{2} \mathrm{H} k_{-a} \\
\text { or } \mathrm{E}_{2}^{-} & =\frac{K_{a}\left(\mathrm{E}_{2} \mathrm{H}\right)}{\left(\mathrm{H}^{+}\right)} .
\end{aligned}
$$

From (4), (5), (6), (7), and (8) we get

$$
\begin{aligned}
\mathrm{E}_{t 2} & =\mathrm{E}_{2} \mathrm{H}+\mathrm{E}_{2}{ }^{-}+\mathrm{E}_{2} \mathrm{H}_{1}{ }^{+}+\mathrm{E}_{2} \mathrm{H}[\mathrm{A} \beta] \\
& =\frac{K_{2} K_{1}}{(\mathrm{AcCoA})(\mathrm{Ch})}\left(1+\frac{K_{a}}{\mathrm{H}^{+}}+\frac{\mathrm{H}^{+}}{K_{b}}+(\mathrm{A} \beta) K_{i}\right) \mathrm{X}_{2} .
\end{aligned}
$$

$\mathrm{X}_{2}$ and $\mathrm{X}_{3}$ are related by

$$
\mathrm{X}_{3}=\frac{\mathrm{X}_{2}}{K_{3}(\mathrm{AcCoA})}
$$

where $K_{3}=k_{-3} / k_{3}$.

Since $\mathrm{E}_{t}=\mathrm{E}_{t 2}+\mathrm{X}_{1}+\mathrm{X}_{2}+\mathrm{X}_{3}$,

$$
\begin{aligned}
& \mathrm{E}_{t}=\mathrm{X}_{2}\left(\frac{K_{2} K_{1}}{\operatorname{AcCoA}(\mathrm{Ch})}\left(1+\frac{K_{a}}{\mathrm{H}_{1}{ }^{+}}+\frac{\mathrm{H}_{1}^{+}}{K_{b}}+(b A) K_{i}\right)+\frac{K_{1}}{\mathrm{Ch}}+1+\frac{1}{K_{3}(\mathrm{AcCoA})}\right) \\
& \text { or } \mathrm{X}_{2}=\frac{\mathrm{E}_{t}(\mathrm{Ch})(\mathrm{AcCoA})}{\left(K_{2} K_{1}\left(1+\left(K_{a} / \mathrm{H}_{1}^{+}\right)+\left(\mathrm{H}_{1}^{+} / K_{b}\right)+(\mathrm{A} \beta) K_{i}\right)+K_{1}(\mathrm{AcCoA})+\mathrm{Ch}(\mathrm{AcCoA})+\mathrm{Ch} / K_{3}\right)} \\
& \mathrm{X}_{2}=\frac{\mathrm{E}_{t}(\mathrm{Ch})(\mathrm{AcCoA})}{\left(K_{2} K_{1}\left(1+\left(K_{a} / \mathrm{H}_{1}{ }^{+}\right)+\left(\mathrm{H}_{1}{ }^{+} / K_{b}\right)+(\mathrm{A} \beta) K_{i}\right)+K_{1}(\mathrm{AcCoA})+\mathrm{Ch}(\mathrm{AcCoA})+\mathrm{Ch} / K_{3}\right)} \\
& h_{1}=\frac{\mathrm{H}_{1}^{+}}{K_{a}} \\
& \mathrm{X}_{2}=\frac{\mathrm{E}_{t}(\mathrm{Ch})(\mathrm{AcCoA}) /\left(S_{2 \mathrm{ref}} S_{3 \mathrm{ref}}\right)}{\left(\left(K_{2} K_{1} / S_{2 \mathrm{ref}} S_{3 \mathrm{ref}}\right)\left(1+\left(1 / h_{1}\right)+\left(K_{a} / K_{b}\right) h_{1}+(\mathrm{A} \beta) K_{i}\right)+\left(K_{1} / S_{2 \mathrm{ref}} S_{3 \mathrm{ref}}\right)(\mathrm{AcCoA})+\left(\mathrm{Ch}(\mathrm{AcCoA}) / S_{2 \mathrm{ref}} S_{3 \mathrm{ref}}\right)+\left(\mathrm{Ch} / K_{3}\right)\left(1 / S_{2 \mathrm{ref}} S_{3 \mathrm{ref}}\right)\right)} \\
& \mathrm{X}_{2} \\
& =\frac{\mathrm{E}_{t}(\mathrm{Ch})(\mathrm{AcCoA}) /\left(S_{2 \mathrm{ref}} S_{3 \mathrm{ref}}\right)}{\left(\left(K_{2} K_{1} / S_{2 \mathrm{ref}} S_{3 \mathrm{ref}}\right)\left(1 / h_{1}\right)\left(h_{1}+1+\left(K_{a} / K_{b}\right) h_{1}^{2}+\left((\mathrm{A} \beta) / \mathrm{A} \beta_{\mathrm{ref}}\right) h_{1} K_{i}\left(\mathrm{~A} \beta_{\mathrm{ref}}\right)\right)+\left(K_{1} / S_{2 \mathrm{ref}} S_{3 \mathrm{ref}}\right)(\mathrm{AcCoA})+\left(\mathrm{Ch}(\mathrm{AcCoA}) / S_{2 \mathrm{ref}} S_{3 \mathrm{ref}}\right)+\left(\mathrm{Ch} / K_{3}\right)\left(1 / S_{2 \mathrm{ref}} S_{3 \mathrm{ref}}\right)\right)} \\
& \mathrm{X}_{2}=\frac{\mathrm{E}_{t} s_{31} s_{21}}{\left(\theta_{2} / h_{1}\left(1+h_{1}+(\mathrm{A} \beta) h_{1} K_{i 1}+\delta h_{1}^{2}\right)+\theta_{3} s_{31}+\theta_{5} s_{31} s_{21}+\theta_{4} s_{21}\right)} \\
& \mathrm{X}_{2}=\frac{\mathrm{E}_{t} s_{31} s_{21}}{\left(\theta_{2} / h_{1}\left(1+h_{1}\left(1+\mathrm{A} \beta K_{i 1}\right)+\delta h_{1}^{2}\right)+\theta_{3} s_{31}+\theta_{5} s_{31} s_{21}+\theta_{4} s_{21}\right)} .
\end{aligned}
$$

Since $r_{1}=K_{2}^{\prime} \mathrm{X}_{2}$, therefore

$$
\begin{aligned}
& r_{1} \\
& =\frac{\theta_{1} s_{31} s_{21}}{\theta_{2} / h_{1}\left(1+h_{1}\left(1+\mathrm{A} \beta K_{i 1}\right)+\delta h_{1}^{2}\right)+\theta_{3} s_{31}+\theta_{4} s_{21}+\theta_{5} s_{31} s_{21}},
\end{aligned}
$$

where $\mathrm{A} \beta$ is the generated $\beta$-amyloid aggregates concentration in the dimensionless form and $K_{i}$ is the dimensionless equilibrium rate constant for the first proposed inhibition mechanism (Figure 3(a)). Table 1 summarizes the nine ordinary-differential equations of $2 \mathrm{E} 2 \mathrm{C}$ model considering ChAT-inhibition effect by $\beta$-amyloid based on the previous 
TABLE 1: Dimensionless forms of the ordinary differential equations of ChAT inhibition effects by $\beta$-amyloid aggregates of kinetic mechanism 1.

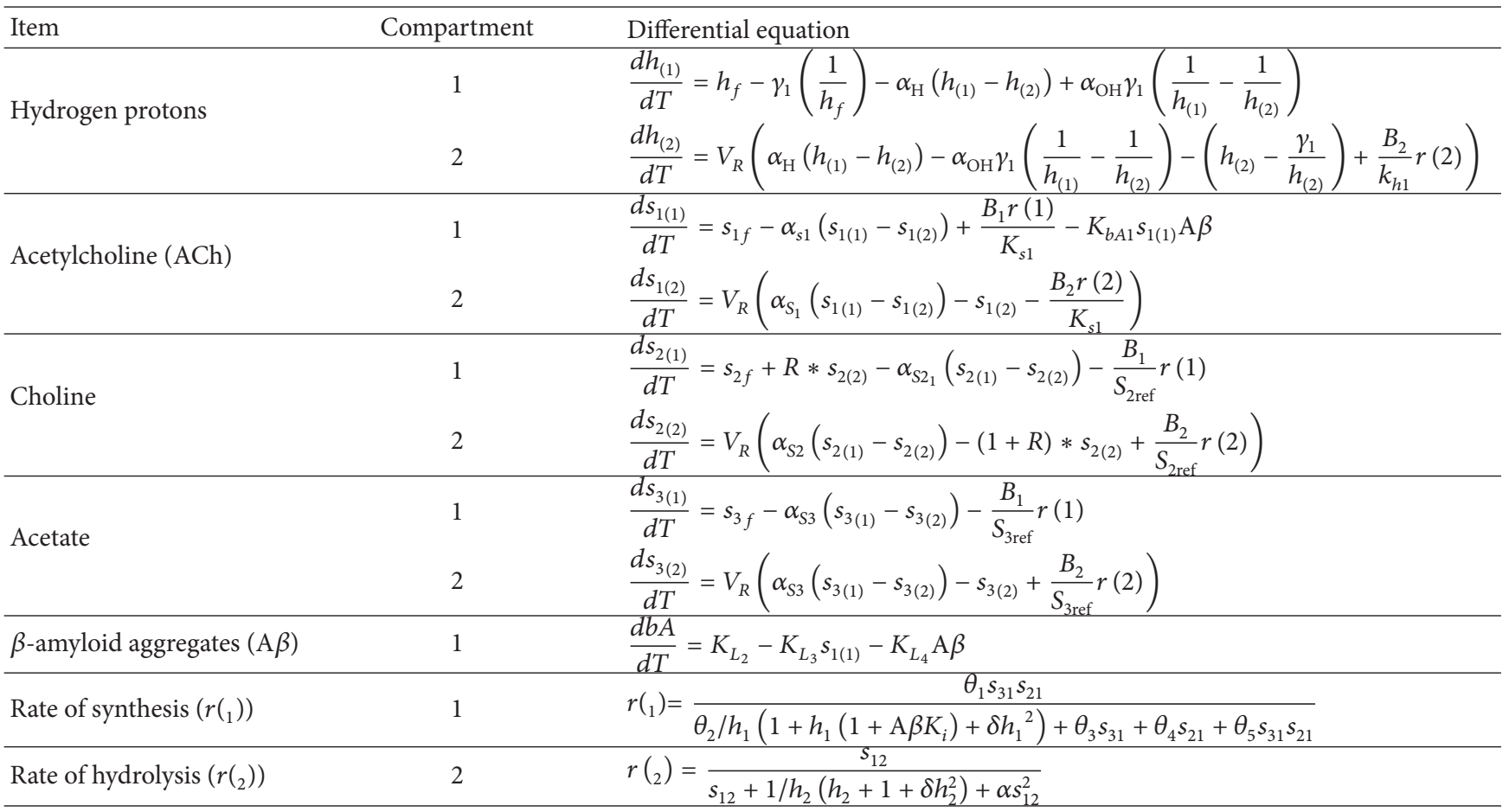

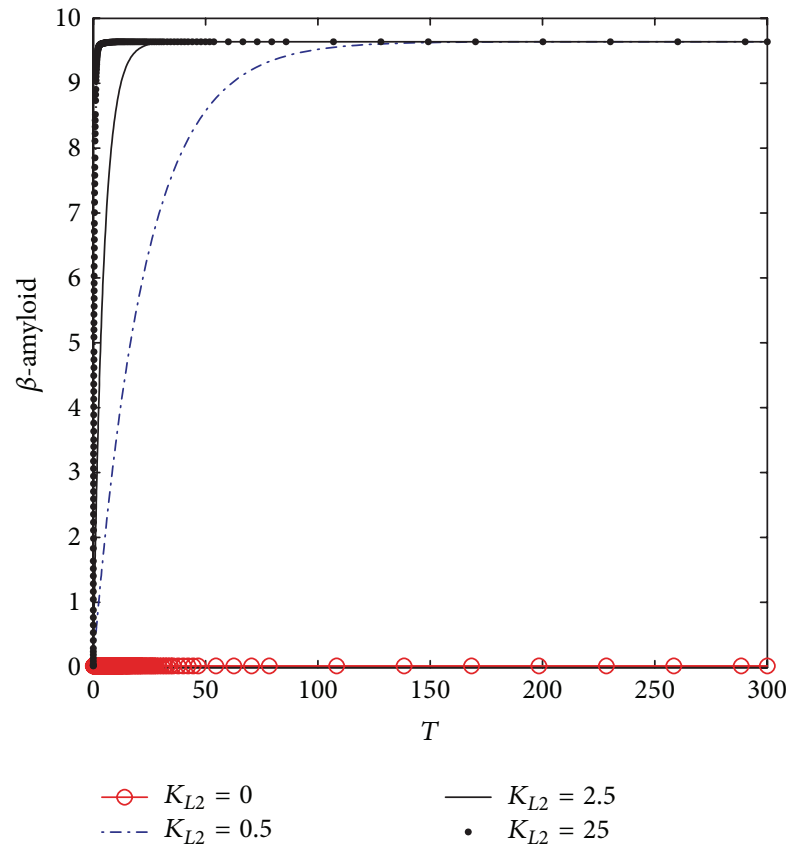

Figure 4: Time course of $\beta$-amyloid at different $K_{L 2}$ according to kinetic mechanism 1.

kinetic mechanism (1), and Table 2 gives the values of kinetic parameters.

3.1.1. $\beta$-Amyloid Generation. Figure 4 shows the dynamic behavior of $\beta$-amyloid aggregates concentrations. It is observed that, at $K_{L 2}=0$, no $\beta$-amyloid aggregate is produced. However, when $K_{L 2}$ increases to 0.5 (corresponding to $10 \mathrm{nM})$, the concentration of generated $\beta$-amyloid increases in the period $0-150$ (corresponding to $0-15 \mathrm{hr}$ ) to reach the plateau at 9.75 (corresponding to $185 \mathrm{nM}$ ). However, when $K_{L 2}=2.5$ (corresponding to $50 \mathrm{nM}$ ), the produced $\beta$-amyloid increases rapidly to reach the plateau at the previous concentrations which is $185 \mathrm{nM}$ but through a shorter time which is 15 (corresponding to $1.5 \mathrm{hr}$ ) and remains constant until the end of the incubation period which is 30 (corresponding to $30 \mathrm{hr}$ ). When $K_{L 2}$ increases to reach the maximum value which is 25 (corresponding to $500 \mathrm{nM}$ ), the generated $A \beta$ increases with a rate faster than the previous rates at $K_{L 2}=0.5$ and 0.75 to reach the plateau in a period of 5 (corresponding to $0.5 \mathrm{hr}$ only).

3.1.2. Rate of ACh Synthesis and Hydrolysis. Figure 5(a) shows the dynamics behavior of ACh synthesis (Rate 1) catalyzed by the enzyme ChAT. It is observed that Rate 1 reaches steady state at a high value which is 0.01375 at $K_{L 2}=0$, where no $\beta$ amyloid aggregate is produced; however, when $K_{L 2}$ increases to $0.5,2.5$, and 25 , Rate 1 decreases significantly to reach a steady state around 0.0104 . It is observed that the final value of Rate 1 at the end of the period 0-300 corresponding to 0$30 \mathrm{hr}$ does not change with $K_{L 2}$ reflecting the neglected effect of the generated $\beta$-amyloid aggregates in this period. The rate of ACh synthesis is lowered by $25 \%$ through the effect of $\beta$ amyloid on ChAT. Figure 5(b) shows that there is no effect of $K_{L 2}$ on the rate of hydrolysis (Rate 2) indicating that Rate 2 is independent of the change of $K_{L 2}$ in the kinetic mechanism.

These results are compatible with the experimental results obtained by Nunes-Tavares et al. [10] who showed that $\beta$ amyloid aggregates could bind to a significant portion of 
TABLE 2: Values of the kinetic parameters.

\begin{tabular}{|c|c|c|}
\hline Parameter & Value & Reference \\
\hline$\overline{\theta_{1}}$ & $5.2(0.1)$ & {$[5,6,29]$} \\
\hline$\theta_{2}$ & 12 & {$[5,6]$} \\
\hline$\theta_{3}$ & 1000 & {$[5,6]$} \\
\hline$\theta_{4}$ & 5 & {$[5,6]$} \\
\hline$\theta_{5}$ & 1 & {$[5,6]$} \\
\hline$\alpha$ & 0.5 & [30-34] \\
\hline$\delta$ & 1 & {$[30-34]$} \\
\hline$k_{h 1}$ & $\begin{array}{c}1.066 * 10^{-6} \mathrm{kMole} / \mathrm{m}^{3} \\
\left(\mu \text { Mole } / \mathrm{mm}^{3}\right)\end{array}$ & [30-34] \\
\hline$K_{s 1}$ & $50.33 \mu$ Mole $/ \mathrm{L}$ & [30-34] \\
\hline$S_{2 \text { ref }}$ & $100 \mu$ Mole $/ \mathrm{L}$ & {$[35]$} \\
\hline$S_{3 \text { ref }}$ & $1 \mu$ Mole $/ \mathrm{L}$ & {$[35]$} \\
\hline$B_{1}$ & $\begin{array}{c}5.033 \times 10^{-5} \mathrm{kMole} / \mathrm{m}^{3} \\
\left(\mu \text { Mole } / \mathrm{mm}^{3}\right)\end{array}$ & {$[30]$} \\
\hline$B_{2}$ & $\begin{array}{c}5.033 \times 10^{-5} \mathrm{kMole} / \mathrm{m}^{3} \\
\left(\mu \text { Mole } / \mathrm{mm}^{3}\right)\end{array}$ & {$[30]$} \\
\hline$\alpha_{\mathrm{H}^{+}}$ & 2.25 & {$[33]$} \\
\hline$\alpha_{\mathrm{OH}^{-}}$ & 0.5 & {$[33]$} \\
\hline$\alpha_{S_{1}}$ & 1.5 & {$[33]$} \\
\hline$\alpha_{S_{2}}$ & 1.5 & {$[33]$} \\
\hline$\alpha_{S_{3}}$ & 1 & {$[33]$} \\
\hline$V_{R}$ & 1.2 & {$[33]$} \\
\hline $\mathrm{pH}_{f}$ & 8.2 & {$[35]$} \\
\hline$s_{1 f}$ & 15 & {$[30]$} \\
\hline$s_{2 f}$ & 1.15 & {$[30]$} \\
\hline$s_{3 f}$ & 3.9 & {$[30]$} \\
\hline$\gamma_{1}$ & 0.01 & {$[30-34]$} \\
\hline$R$ & 0.8 & {$[36,37]$} \\
\hline$K_{b A \text { ref }}$ & $20 \mathrm{nM} / \mathrm{h}$ & {$[22,28]$} \\
\hline$K_{L 2}$ & Assumed & \\
\hline$K_{L 1}$ & $3 * K_{L 2}$ & Assumed \\
\hline$K_{L 3}$ & $0.035 K_{L 2}$ & Assumed \\
\hline$K_{L 4}$ & $0.176 K_{L 3}$ & Assumed \\
\hline$K_{i 1}$ & 10.015 & Assumed \\
\hline$K_{b A 1}$ & 0.05 & Assumed \\
\hline$T_{\text {ref }}$ & $0.1 \mathrm{~h}$ & Assumed \\
\hline $\mathrm{A} \beta_{\text {ref }}$ & $20 \mathrm{nM} / \mathrm{L}$ & [23] \\
\hline
\end{tabular}

cholinergic neurons and reduce ChAT activity. It is observed that the reduction in Rate 1 decreases from 0.0105 to 0.000125 which refers to a reduction in ChAT activity of $99.7 \%$ with an increase in $K_{L 2}$ from 0 to 25 (corresponding to $500 \mathrm{nM}$ ). In addition, Nunes-Tavares et al. [10] showed that $\beta$-amyloid aggregates have a very limited effect on the activity of AChE in comparison to ChAT activity which is in agreement with our results shown in Figures 5(a) and 5(b).

3.1.3. ACh Concentrations in Compartments 1 and 2. One of the main physiological symptoms of $\mathrm{AD}$ is a reduction of $\mathrm{ACh}$ production in cholinergic neurons [38]. Therefore, the first step towards validating $\beta$-amyloid aggregates inhibition model is to see whether this physiological effect is reflected in the simulation results or not. As shown in Figure 6, it is an evidence of decreasing $\mathrm{ACh}$ concentration $\left(\mathrm{ACh}_{1}\right)$ level in compartment 1. Figure 6(a) shows the dynamics of $\mathrm{ACh}_{1}$ which reaches steady state at a high value at $K_{L 2}=0$ where $\mathrm{ACh}_{1}$ settles down around 4 (corresponding to $221.5 \mu \mathrm{M}$ ) where no $\beta$-amyloid aggregate is produced, but when $K_{L 2}$ increases to $0.5,2.5$, and 25 , it is observed that $\mathrm{ACh}_{1}$ decreases slightly to reach the steady state at 4.28 (corresponding to $215 \mu \mathrm{M}$ ). It is noted that the final value of rate at the end of the period $0-300$ corresponding to $0-30 \mathrm{hr}$ does not change with $K_{L 2}$ reflecting the neglected effect of the generated $\beta$-amyloid aggregates in this period.

These results are compatible with experimental results obtained by Kar et al. [39] who indicated that the decrease in ChAT activity leads to a reduction in ACh generated in the presynaptic neurons. Furthermore, Zheng et al. [40] indicated that exposure of culture neurons to $\beta$-amyloid aggregates leads to a decrease in ChAT activity. However, Pedersen and Blusztajn [20] showed that only acetyl-coA not ChAT activity is affected negatively when exposed to $\beta$ amyloid aggregates leading to reduction of generated ACh similar to the rate of ACh hydrolysis shown in Figure 5(b) which exhibits no effect of $K_{L 2}$ where $\mathrm{ACh}_{2}$ does not change with any change in $K_{L 2}$. The absence of any observable effects in $\mathrm{ACh}_{2}$ is mostly likely due to the relative magnitude of the ACh synthesis rate $\left(r_{1}\right)$ compared to the magnitude of other transport phenomena within the model. Focusing on the kinetics in compartment $2, \mathrm{ACh}_{2}$ level is governed mainly by two processes: membrane diffusion of ACh from compartment 1 and the rate of ACh degradation $\left(r_{2}\right)$ in compartment 2. The transport of ACh into compartment 2 through membrane diffusion is observed to slightly decrease due to reduced $\mathrm{ACh}_{1}$ levels from $\beta$-amyloid aggregates inhibition. On the other hand, the rate of ACh breakdown is maintained the same. It is expected that the influx of ACh into compartment 2 is approximately an order of magnitude higher than the consumption of $\mathrm{ACh}\left(r_{2}\right)$ in that compartment. This means that although the influx of ACh into compartment 2 is limited by $\beta$-amyloid aggregates inhibition, the fact that $r_{2}$ is so small in comparison infers that the overall level of $\mathrm{ACh}_{2}$ will not be affected much.

3.1.4. Choline Concentrations in Compartments 1 and 2. Figures 7(a) and 7(b) show the dynamic response for choline concentrations in compartments $1\left(\mathrm{Ch}_{1}\right)$ and $2\left(\mathrm{Ch}_{2}\right)$, respectively. It is observed that there is no effect of $K_{L 2}$ on the behavior of $\mathrm{Ch}_{1}$. This reflects that the uptake of choline to compartment 1 is not affected by any change in $\beta$-amyloid aggregates through the interaction between ChAT and $\beta$ amyloid aggregates via the relevant kinetic mechanism. This result is compatible with the experimental results obtained by Nunes-Tavares et al. [10] who showed that there is no effect of $\beta$-amyloid oligomers on choline uptake. Figure 7(b) shows that $K_{L 2}$ does not affect $\mathrm{Ch}_{2}$. In other words $\mathrm{ChAT}$ inhibition by $\beta$-amyloid aggregates in compartment 1 does not affect AChE activity in compartment 2 . 


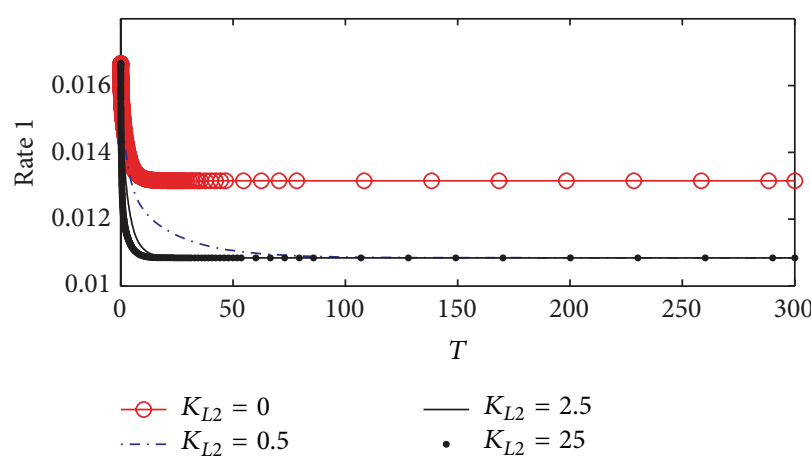

(a)

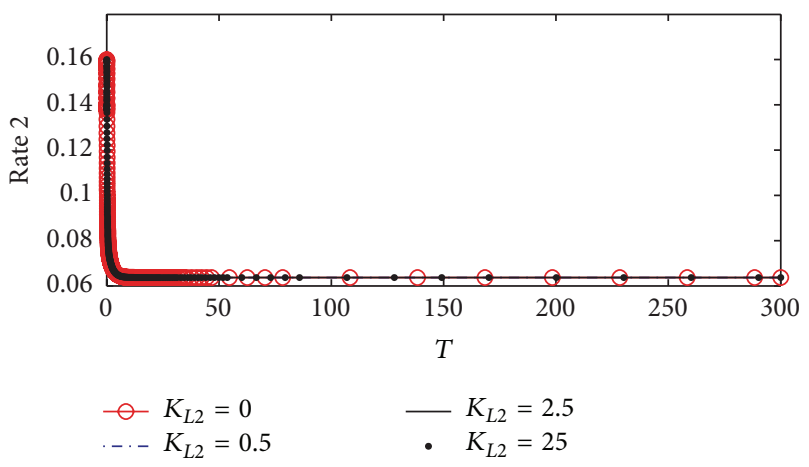

(b)

FIGURE 5: Time course according to kinetic mechanism 1 of (a) rate of ACh synthesis (Rate 1) and (b) rate of ACh hydrolysis (Rate 2) at different $K_{L 2}$.

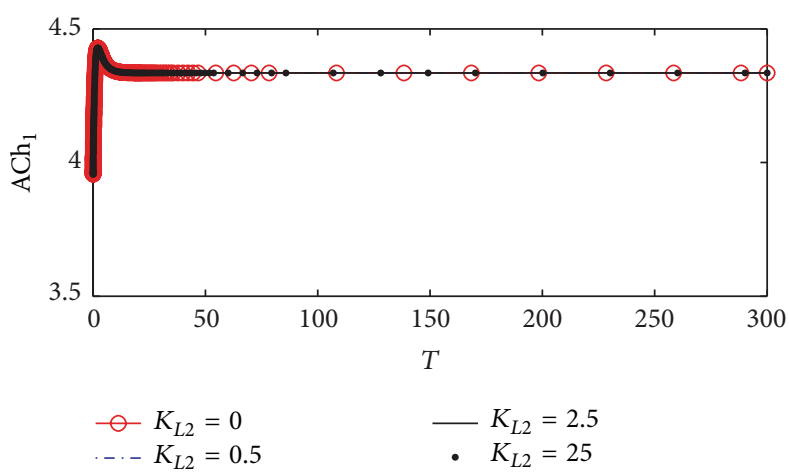

(a)

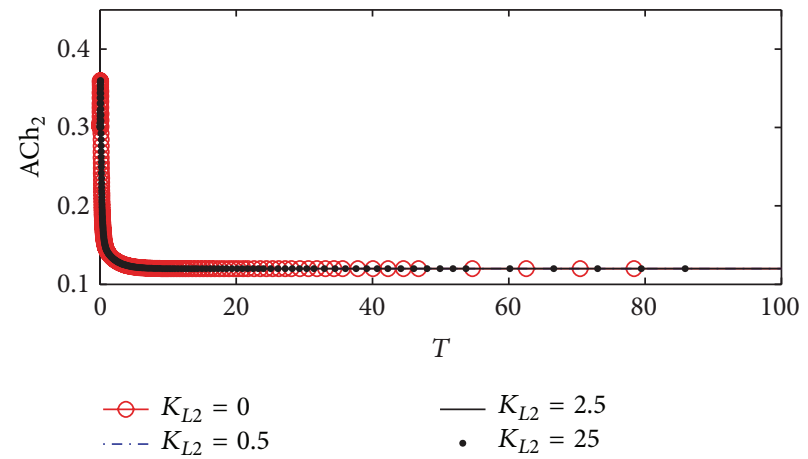

(b)

FIGURE 6: Time course according to kinetic mechanism 1 of (a) ACh concentration in compartment $1\left(\mathrm{ACh}_{1}\right)$ and (b) ACh concentration in compartment $2\left(\mathrm{ACh}_{2}\right)$ at different $K_{L 2}$ values.

3.1.5. Acetate Concentrations in Compartments 1 and 2. Figure 8 shows the dynamic response for acetate concentrations in compartments $1\left(\mathrm{Ac}_{1}\right)$ and $2\left(\mathrm{Ac}_{2}\right)$. Figure $8(\mathrm{a})$ shows that $\mathrm{Ac}_{1}$ increases from 8.25 at the beginning of the period and then it reaches the steady state value which is 9.51 (corresponding to $9.51 \mu \mathrm{M}$ ) when $K_{L 2}$ increases to 0.5 , 0.75 , and $1 . \mathrm{Ac}_{1}$ increases slightly due to ChAT inhibition and accumulates due to low consumption of acetates by ChAT for synthesizing $\mathrm{ACh}$. However, $K_{L 2}$ does not affect $\mathrm{Ac}_{1}$ since the steady state behavior of $A c_{1}$ is obtained when $K_{L 2}$ is higher than zero. Figure $8(\mathrm{~b})$ shows that there is no influence of $K_{L 2}$ on $\mathrm{Ac}_{2}$ which is the same as $\mathrm{Ch}_{2}$ and Rate 2 reflecting the negligible effect of $K_{L 2}$ on compartment 2 through the proposed kinetic mechanism 1 .

3.1.6. $\mathrm{pH}$ in Compartments 1 and 2. Figure 9 shows the dynamic response of $\mathrm{pH}$ in both compartments $1\left(\mathrm{pH}_{1}\right)$ and $2\left(\mathrm{pH}_{2}\right)$. Figure 9 (a) shows that $\mathrm{pH}_{1}$ is affected very slightly with changes in $K_{L 2}$ indicating that the inhibition of ChAT activity with the proposed kinetic mechanism 1 has a low effect on changing $\mathrm{pH}_{1}$. Figure $8(\mathrm{~b})$ shows a negligible effect of $K_{L 2}$ on $\mathrm{pH}_{2}$ which is the same as the behaviors of $\mathrm{Ch}_{2}$ and Rate 2 explained previously. According to kinetic mechanism $1, \beta$-amyloid aggregates promote a major reduction in ChAT activity while all other components in $\mathrm{ACh}$ cholinergic system remain unaffected.
The effect of $\beta$-amyloid aggregates inhibition on the remaining variables ( $\mathrm{pH}$ and $\mathrm{Ac}$ ) is observed to be negligible within the time frame studied. One likely explanation is that the feed concentrations of these chemical components into the $2 \mathrm{E} 2 \mathrm{C}$ system are all much larger in magnitude compared to that of ACh. While they all have indirect dependence on the activity of ChAT through changes in $\mathrm{ACh}_{1}$ concentration, the reduction in $\mathrm{ACh}$ is too small to produce a significant effect on the concentration of these components.

\section{Kinetic Mechanism 2: Competitive Inhibition of $\beta$-Amyloid Aggregates with Enzyme Intermediate Complex $\mathrm{X}_{2}$}

4.1. Formulation of Kinetic Mechanism 2. In this kinetic mechanism, there is a competitive inhibition of $\beta$-amyloid aggregates with enzyme intermediate complex $\mathrm{X}_{2}$. During ACh synthesis as shown in Figure 3(b), the modified rate equation can be derived as shown below.

$\mathrm{X}_{1}$ and $\mathrm{X}_{2}$ are related through the following expressions:

$$
\begin{aligned}
\mathrm{X}_{1}(\mathrm{Ch}) k_{1} & =\mathrm{X}_{2} k_{-1} \\
\text { or } \mathrm{X}_{1} & =\frac{K_{1}}{\mathrm{Ch}} \mathrm{X}_{2},
\end{aligned}
$$

where $K_{1}=k_{-1} / k_{1}$. 


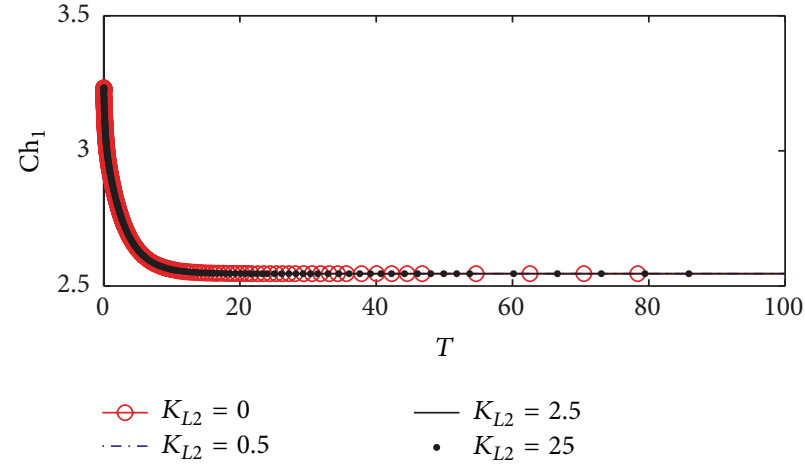

(a)

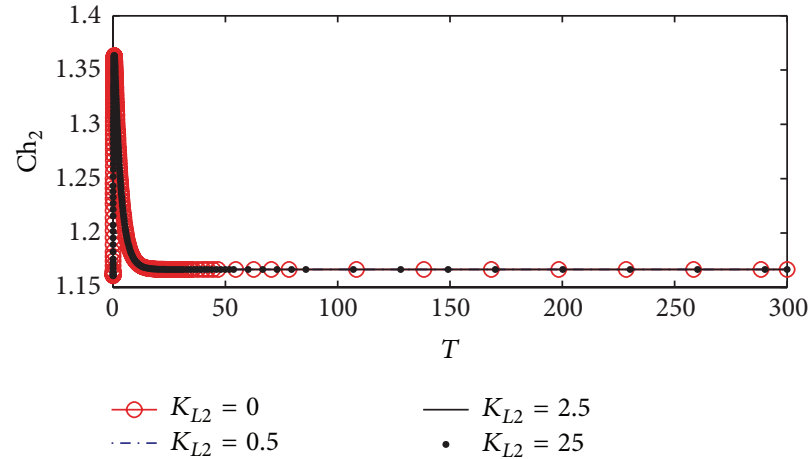

(b)

FIGURE 7: Time course according to kinetic mechanism 1 of (a) choline concentration in compartment $1\left(\mathrm{Ch}_{1}\right)$ and (b) choline concentration in compartment $2\left(\mathrm{Ch}_{2}\right)$ at different $K_{L 2}$ values.

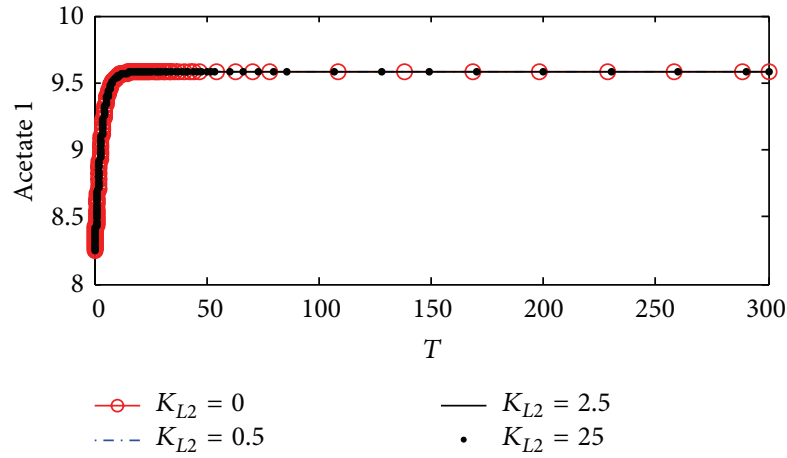

(a)

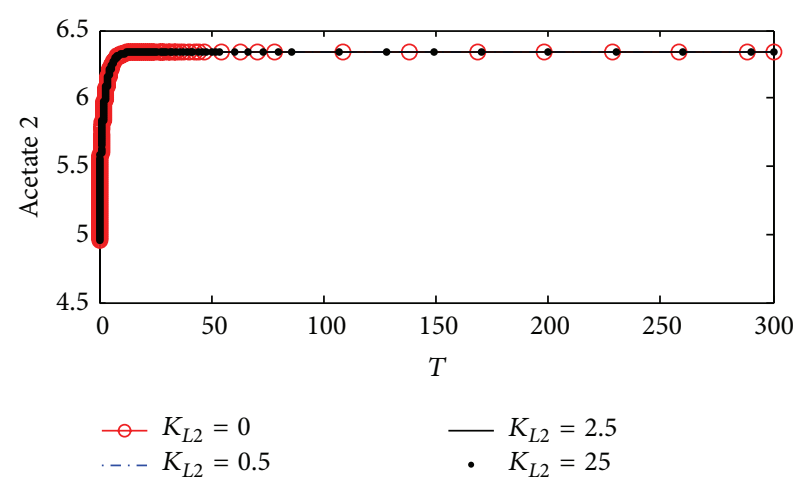

(b)

FIGURE 8: Time course according to kinetic mechanism 1 of (a) acetate concentration in compartment 1 ( $\left.A c_{1}\right)$ and (b) acetate concentration in compartment $2\left(\mathrm{Ac}_{2}\right)$ at different $K_{L 2}$ values.

By the assumption of rapid equilibrium, $\mathrm{E}_{2} \mathrm{H}$ and $\mathrm{X}_{1}$ can be related by

$$
\begin{aligned}
k_{2}(\mathrm{AcCoA}) \mathrm{E}_{2} \mathrm{H} & =k_{-2} \mathrm{X}_{1} \\
\text { or } \mathrm{E}_{2} \mathrm{H} & =\frac{K_{2} \mathrm{X}_{1}}{(\mathrm{AcCoA})}=\frac{K_{2} K_{1}}{(\mathrm{AcCoA})(\mathrm{Ch})} \mathrm{X}_{2},
\end{aligned}
$$

where $K_{2}=k_{-2} / k_{2}$.

From the ionization of $\mathrm{E}_{2} \mathrm{H}$,

$$
\begin{aligned}
\mathrm{E}_{2} \mathrm{H}\left(\mathrm{H}^{+}\right) k_{-b} & =\mathrm{E}_{2} \mathrm{H}^{+} k_{b} \\
\text { or } \mathrm{E}_{2} \mathrm{H}^{+} & =\frac{\left(\mathrm{E}_{2} \mathrm{H}\right)\left(\mathrm{H}^{+}\right)}{K_{b}} .
\end{aligned}
$$

From the deionization of $\mathrm{E}_{2} \mathrm{H}$,

$$
\begin{aligned}
\mathrm{E}_{2}^{-}\left(\mathrm{H}^{+}\right) k_{a} & =\mathrm{E}_{2} \mathrm{H}_{-a} \\
\text { or } \mathrm{E}_{2}^{-} & =\frac{K_{a}\left(\mathrm{E}_{2} \mathrm{H}\right)}{\left(\mathrm{H}^{+}\right)} .
\end{aligned}
$$

From (16), (17), and (18), we get

$$
\begin{aligned}
\mathrm{E}_{t 2} & =\mathrm{E}_{2} \mathrm{H}+\mathrm{E}_{2}^{-}+\mathrm{E}_{2} \mathrm{H}^{+} \\
& =\frac{K_{2} K_{1}}{(\mathrm{AcCoA})(\mathrm{Ch})}\left(1+\frac{K_{a}}{\mathrm{H}^{+}}+\frac{\mathrm{H}^{+}}{K_{b}}\right) \mathrm{X}_{2} .
\end{aligned}
$$

$\mathrm{X}_{2}$ and $\mathrm{X}_{3}$ are related by

$$
\mathrm{X}_{3}=\frac{\mathrm{X}_{2}}{K_{3}(\operatorname{AcCo} \mathrm{A})},
$$

where $K_{3}=k_{-3} / k_{3}$.

Also,

$$
\begin{aligned}
& k_{i} \mathrm{X}_{22}[\mathrm{~A} \beta]=k_{-i} \mathrm{X}_{2}[\mathrm{~A} \beta] \\
& \text { or } \mathrm{X}_{2}[\mathrm{~A} \beta]=K_{i} \mathrm{X}_{22}[\mathrm{~A} \beta],
\end{aligned}
$$

where $K_{i}=k_{i} / k_{-i}$. 


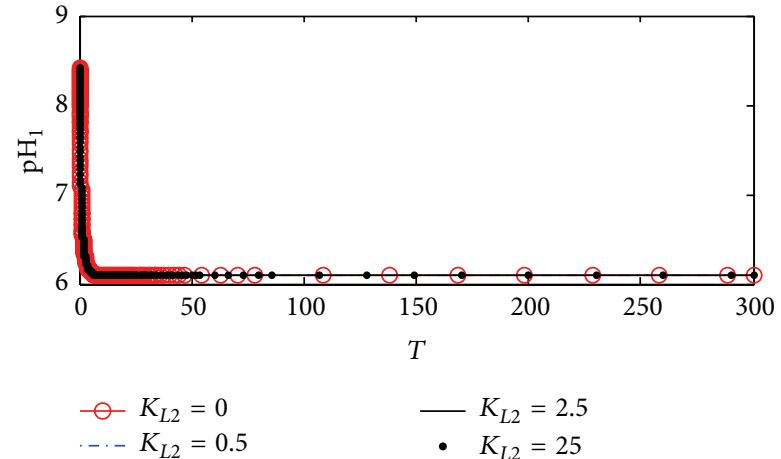

(a)

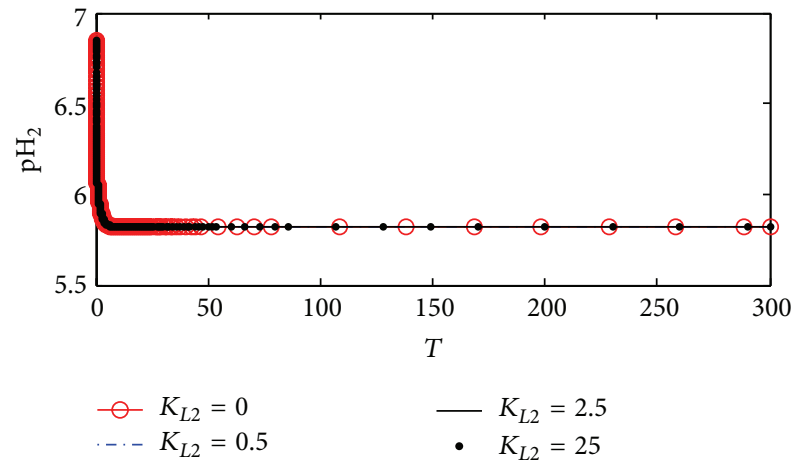

(b)

FIGURE 9: Time course according to kinetic mechanism 1 of (a) $\mathrm{pH}$ in compartment $1\left(\mathrm{pH}_{1}\right)$ and (b) $\mathrm{pH}$ in compartment 2 ( $\left.\mathrm{pH}_{2}\right)$ at different $K_{L 2}$ values.

Since $\mathrm{E}_{t}=\mathrm{E}_{t 2}+\mathrm{X}_{1}+\mathrm{X}_{2}+\mathrm{X}_{3}+\mathrm{X}_{2}[\mathrm{~A} \beta]$, we get

$$
\begin{aligned}
\mathrm{E}_{t} & =\mathrm{X}_{2}\left(\frac{K_{2} K_{1}}{\operatorname{AcCoA}(\mathrm{Ch})}\left(1+\frac{K_{a}}{\mathrm{H}_{1}^{+}}+\frac{\mathrm{H}_{1}^{+}}{K_{b}}\right)+\frac{K_{1}}{\mathrm{Ch}}+1+\frac{1}{K_{3}(\mathrm{AcCoA})}+(\mathrm{A} \beta) K_{i}\right) \\
\text { or } \mathrm{X}_{2} & =\frac{\mathrm{E}_{t}(\mathrm{Ch})(\mathrm{AcCoA})}{\left(K_{2} K_{1}\left(1+\left(K_{a} / \mathrm{H}_{1}^{+}\right)+\left(\mathrm{H}_{1}^{+} / K_{b}\right)\right)+K_{1}(\mathrm{AcCoA})+\mathrm{Ch}(\mathrm{AcCoA})+\left(\mathrm{Ch} / K_{3}\right)+(\mathrm{A} \beta) K_{i} \operatorname{Ch}(\mathrm{AcCoA})\right)} .
\end{aligned}
$$

Since $R_{1}=K_{2}^{\prime} \mathrm{X}_{2}$, therefore,

$$
\begin{aligned}
& r_{1} \\
& =\frac{\theta_{1} s_{21} s_{31}}{\left(\theta_{2} / h_{1}\left(h_{1}+1+\delta h_{1}^{2}\right)+\theta_{3} s_{31}+\theta_{4} s_{21}+\theta_{5} s_{21} s_{31}\left(1+K_{I 1} \mathrm{~A} \beta\right)\right)},
\end{aligned}
$$

where $\mathrm{A} \beta$ is the concentration of generated $\beta$-amyloid aggregates in the dimensionless form and $K_{I 1}$ is the dimensionless equilibrium rate constant for the second proposed inhibition mechanism shown in Figure 3(b). In the next section, the results presented are based on the previous equation of $r_{1}$ replacing the $r_{1}$ in Table 1 while all other equations remain the same. The kinetic parameter values are given in Table 2.

4.2. Results of Kinetic Mechanism 2. Incorporating the rate of ChAT synthesis $r_{1}$ (21) inhibited by $\beta$-amyloid aggregates derived from the kinetic mechanism (2) into the 9th dimension 2E2C model shown in Table 1 , the effect of $\beta$ amyloid aggregates on $\mathrm{ACh}$ neurocycle is investigated to check the feasibility of kinetic mechanisms as a descriptor for the interaction between ChAT activity and $\beta$-amyloid aggregates.

4.2.1. $\beta$-Amyloid Generation. Figure 10 shows the dynamic behavior of $\beta$-amyloid aggregates produced in compartment 1 . It is clear that at $K_{L 2}=0$, where there is no inlet $\beta$-amyloid, there is no generation of $\beta$-amyloid aggregates. However, when $K_{L 2}$ increases to 0.5 (corresponding to $10 \mathrm{nM}$ ), $\beta$ amyloid aggregate is produced to reach 10 (corresponding to $200 \mathrm{nM}$ ) after a time of 150 (corresponding to $15 \mathrm{hr}$ ); then it becomes constant where there is no more generation until the end of the incubation period (300) corresponding to $30 \mathrm{hr}$. In addition, Figure 10 shows that when $K_{L 2}$ increases to 2.5 (corresponding to $50 \mathrm{nM}$ ), $\beta$-amyloid aggregates are generated faster than that at $K_{L 2}=0.5$, where $\beta$-amyloid aggregates reach the stationery steady state after 15 (corresponding to $1.5 \mathrm{hr}$ ); then it does not change until the end of the incubation period. Furthermore, at $K_{L 2}=25$ (corresponding to $500 \mathrm{nM}$ ), $\beta$-amyloid aggregates are produced much faster than before where it reaches the steady state value only after a dimensionless time of 7 (corresponding to 42 minutes). Comparing the dynamic behaviors of $\beta$-amyloid aggregates in kinetic mechanism 2 and kinetic mechanism 1, it is observed that the final steady state value of kinetic mechanism 2 is higher than that of kinetic mechanism 1 . The increase of final $\beta$-amyloid aggregates might lead to changes in other state variables of the system.

4.2.2. Rates of ACh Synthesis and Hydrolysis. Figure 11 shows the dynamic behavior of rate of ACh synthesis catalyzed by ChAT (Rate 1) and rate of ACh hydrolysis catalyzed by AChE (Rate 2). Figure 11(a) shows that Rate 1, at no $\beta$ amyloid aggregates production, where $K_{L 2}=0$, decreases from 0.016 at the beginning of process to reach 0.0138 after passing 20 (corresponding to $2 \mathrm{hr}$ ); then it becomes constant until the end of the period. However, when ChAT activity is reduced according to kinetic mechanism 2 at $K_{L 2}=0.5$ (corresponding to $10 \mathrm{nM}$ ), Rate 1 decreases significantly as shown in Figure 11(a) to reach 0.0103 at the end of the period but it reaches the steady state slower than that at $K_{L 2}=0$ where it takes time of 100 (corresponding to $10 \mathrm{hr}$ ) to reach 


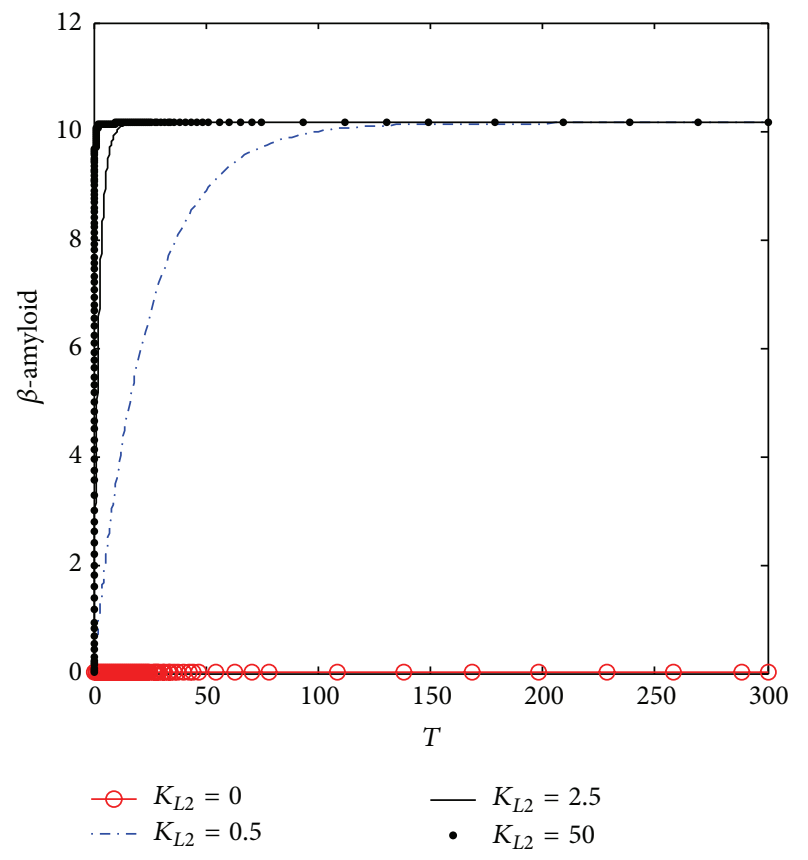

FIGURE 10: Time course of generated $\beta$-amyloid aggregates at different $K_{L 2}$ (according to kinetic mechanism 2).

the plateau. Furthermore, when $K_{L 2}$ increases to 2.5 and 50 (corresponding to 50 and $1000 \mathrm{nM}$, resp.), the generated $\beta$-amyloid takes the same behavior where both decrease with the same rate but faster than that at $K_{L 2}=0.5$. It is observed that the reduction in Rate 1 decreases from 0.01375 to 0.0105 which refers to a reduction in ChAT activity of $24.7 \%$ with an increase of $K_{L 2}$ from 0 to 25 (corresponding to $500 \mathrm{nM}$ ). Figure 11(b) shows that the effect of changing $K_{L 2}$ on Rate 2 is negligible according to the kinetic mechanism 2 indicating the same behavior as kinetic mechanism 1 as shown previously in Figure 7(b).

4.2.3. ACh Concentrations in Compartments 1 and 2. Figure 12(a) shows the dynamics of $\mathrm{ACh}_{1}$ with the rate of ChAT activity inhibition $r_{1}$ based on kinetic mechanism 2. It is observed that at $K_{L 2}=0.5 \mathrm{ACh}_{1}$ reduces from 4.3 (corresponding to $216.419 \mu \mathrm{M}$ ) at the beginning of $\beta$ amyloid aggregates incubation to reach 3.15 (corresponding to $158.5 \mu \mathrm{M})$ after passing $100(10 \mathrm{hr})$ and it keeps at this value until the end of the period which is 300 (corresponding to $30 \mathrm{hr}$ ). Comparing $\mathrm{ACh}_{1}$ at $K_{L 2}=0.5$ to that in the first kinetic mechanism in Figure 6(a), it is observed that the rate of ChAT activity affected by the interaction between competitive inhibitions of $\beta$-amyloid aggregates with enzyme intermediate complex $\mathrm{X}_{2}$ in kinetic mechanism 2 leads to a more reduction in $\mathrm{ACh}_{1}$. At $K_{L 2}=2.5$ and 50, the reduction of $\mathrm{ACh}_{1}$ is faster than that at $K_{L 2}=0.5$ where it occurs after passing 15 and 10 (corresponding to 1.5 and $1 \mathrm{hr}$, resp.); then $\mathrm{ACh}_{1}$ remains at steady state around 3.15 (corresponding to $158.5 \mu \mathrm{M}$ ) indicating that inhibition of ChAT activity by $\beta$ amyloid aggregates reached its maximum limit. Figure 12(b) shows that $\mathrm{ACh}_{2}$ is not affected significantly with the change of $K_{L 2}$, which is the same as in kinetic mechanism 1 as shown in Figure 6(b).

4.2.4. Choline Concentrations in Compartments 1 and 2. Figures 13(a) and 13(b) illustrate the time course of choline concentrations in compartments 1 and 2, respectively. It is observed that $K_{L 2}$ has no effect on both $\mathrm{Ch}_{1}$ and $\mathrm{Ch}_{2}$ indicating that the inhibition of ChAT activity by $\beta$-amyloid aggregate does not affect choline uptake in compartment 1 and choline produced from hydrolysis in compartment 2 following the same behavior in kinetic mechanism 1 as shown previously in Figures 7(a) and 7(b).

4.2.5. Acetate Concentrations in Compartments 1 and 2. Figure 14(a) shows the effect of changing $K_{L 2}$ in terms of the inhibition of ChAT activity according to kinetic mechanisms 2 on intracellular concentration of acetate. At $K_{L 2}=0$, $\mathrm{Ac}_{1}$ increases through the first $30(3 \mathrm{hr})$ and reaches steady state around 9.52 (corresponding to $9.52 \mu \mathrm{M}$ ) indicating that inhibition of ChAT activity by $\beta$-amyloid aggregates reached its maximum limit. However, after incorporating $\beta$-amyloid generation in terms of $K_{L 2}=0.5,2.5$, and 50 (corresponding to $10,25,1000 \mathrm{nM}$ ), there is a significant decrease in $A_{1}$, where the final steady state concentration of $\mathrm{Ac}_{1}$ is around 8.95 (corresponding to $8.95 \mu \mathrm{M}$ ). It is clear that competitive inhibition of $\beta$-amyloid aggregates with enzyme intermediate complex $\mathrm{X}_{2}$ in kinetic mechanism 2 has more effect on $\mathrm{Ac}_{1}$ than that in kinetic mechanism 1. Figure 14(b) shows that $\mathrm{Ac}_{2}$ is affected clearly with any increase in inlet $\beta$-amyloid aggregates concentrations $\left(K_{L 2}\right)$ where, at $K_{L 2}=0$, the steady state of $\mathrm{Ac}_{2}=6.4$ (corresponding to $6.4 \mu \mathrm{M}$ ) while with the increase of $K_{L 2}$ to $0.5,2.5$, and 50 the steady state value of $\mathrm{Ac}_{2}$ will be around 5.6 and not varying with changing $K_{L 2}$ as illustrated in Figure 14(b). This indicates again that inhibition of ChAT activity by $\beta$-amyloid aggregate reaches the maximum effect.

4.2.6. $p H$ in Compartments 1 and 2. Figure 15(a) shows the dynamics of $\mathrm{pH}_{1}$ with changing $K_{L 2}$. It is observed that, at $K_{L 2}=0, \mathrm{pH}_{1}$ decreases from 8.5 at the beginning to settle down around 6.2 at the end of the period. However, as $K_{L 2}$ increases to $0.5,2.5$, and $50, \mathrm{pH}_{1}$ decreases clearly to settle down around 7.75 indicating that the inhibition of ChAT activity by $\beta$-amyloid reaches the maximum limit. It is concluded that the rate of transport of hydrogen protons from compartment 1 to compartment 2 is still higher than the rate of accumulation of hydrogen protons due to the inhibition of ChAT catalytic effect according to kinetic mechanism 2. Figure 15(b) shows the dynamic behavior of $\mathrm{pH}_{2}$ where $\mathrm{pH}_{2}$ increases from 5.85 at $K_{L 2}=0$ to the steady state value of 6.23 with increasing $K_{L 2}$ from 0.5 to 50 .

It is clear that kinetic mechanism 2 in terms of competitive inhibition of $\beta$-amyloid aggregates with enzyme intermediate complex $\mathrm{X}_{2}$ has more effect on $\mathrm{pH}_{1}$ and $\mathrm{pH}_{2}$ than that in kinetic mechanism 1. It is observed that, after time of 100 (corresponding to $10 \mathrm{hr}$ ), there is no effect for any further change of $\beta$-amyloid aggregates production rate ( $K_{L 2}$ from 0.5 to 25 ), where all state variables reach the same 


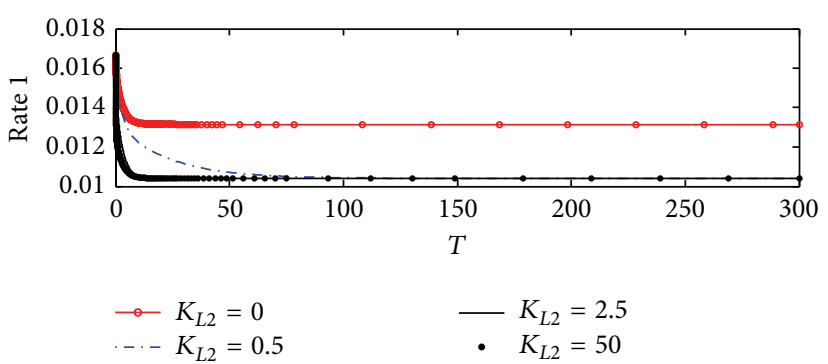

(a)

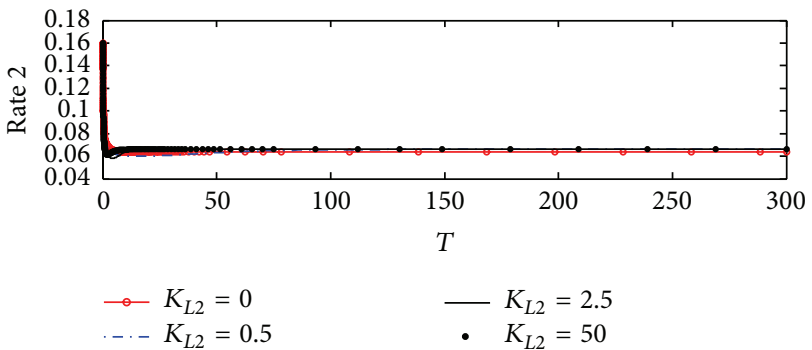

(b)

FIgURE 11: Time course of (a) rate of ACh synthesis (Rate 1) and (b) rate of ACh hydrolysis (Rate 2) at different $K_{L 2}$ (according to kinetic mechanism 2).

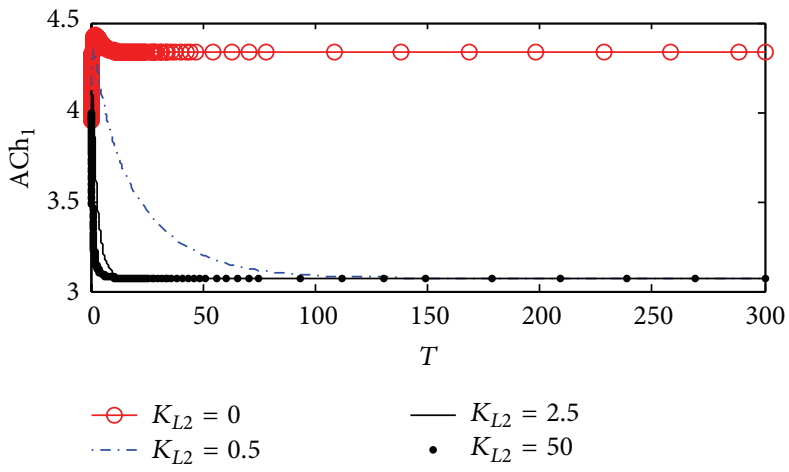

(a)

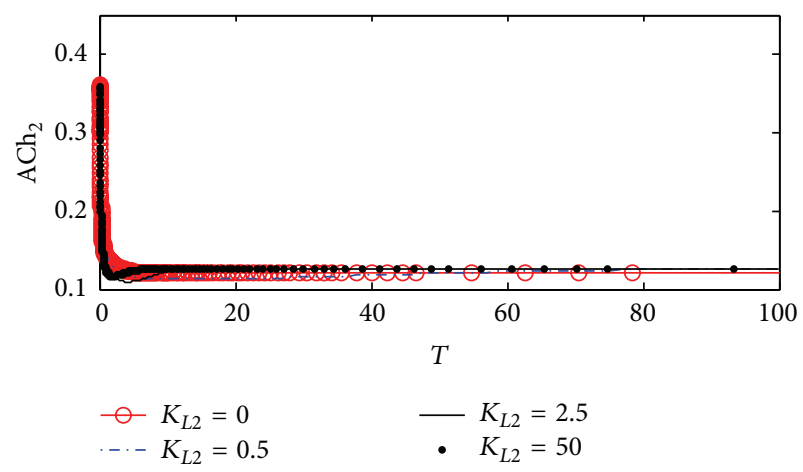

(b)

FIGURE 12: Time course of (a) ACh concentration in compartment $1\left(\mathrm{ACh}_{1}\right)$ and (b) $\mathrm{ACh}$ concentration in compartment $2\left(\mathrm{ACh}_{2}\right)$ at different $K_{L 2}$ values (according to kinetic mechanism 2).

steady state values indicating that the activity of ChAT is fully inhibited. These results are compatible with that obtained by Nunes-Tavares et al. [10] who showed that there is no significant effect for any further $\beta$-amyloid concentration more than $100 \mathrm{nM}$. According to kinetic mechanism 2, $\beta$ amyloid aggregates promote a major reduction in ChAT function, $\mathrm{ACh}_{1}$, acetate 1 and acetate $2, \mathrm{pH}_{1}$, and $\mathrm{pH}_{2}$ while all other components in $\mathrm{ACh}$ cholinergic system remain unaffected.

\section{Kinetic Mechanism 3: Noncompetitive Inhibition of $\beta$-Amyloid Aggregates with All Species ChAT}

5.1. Formulation of Kinetic Mechanism 3. $\beta$-amyloid aggregate inhibitor behaves as a noncompetitive inhibitor and could attack all ChAT species in the synthesis reaction in compartment 1 with the same affinity if the reaction follows either a rapid equilibrium random mechanism or an ordered sequential [41]. Figure 16 shows the kinetic mechanism 3 for the synthesis reaction catalyzed by ChAT where all species in ChAT can be exposed to $\beta$-amyloid aggregates, where $\mathrm{E}=$ ChAT, $\mathrm{I}=\beta$-amyloid aggregates, $\mathrm{A}=$ choline, and $\mathrm{B}=$ acetylcoA. In the same way as the previous kinetic mechanisms 1 and 2 were derived, the final form of the rate of ACh synthesis derived is shown as follows:

$$
\begin{aligned}
& r_{1} \\
& =\frac{\theta_{1} s_{21} s_{31}}{\left(\theta_{2} / h_{1}\left(h_{1}+1+\delta h_{1}^{2}\right)+\theta_{3} s_{31}+\theta_{4} s_{21}+\theta_{5} s_{21} s_{31}\right)\left(1+K_{I 1} \mathrm{~A} \beta\right)} .
\end{aligned}
$$

By using (22) for the rate equation $r_{1}$ in 2E2C of Table 1 and keeping all other equations the same and incorporating $K_{I 1}$ into Table 2 , the effect of $\beta$-amyloid aggregates as an inhibitor for ChAT activity on 2E2C model can be simulated as discussed in the next section.

\subsection{Results of Kinetic Mechanism 3}

5.2.1. $\beta$-Amyloid Aggregates Generation. Figure 17 shows the dynamic response at different $K_{L 2}$ values. At $K_{L 2}=0$ where there is a normal ChAT activity without inhibition, it is observed that there is no $\beta$-amyloid aggregates generated where $\beta$-amyloid concentration $=0$. At $K_{L 2}=0.5, \beta$ amyloid aggregate is produced significantly and increases to 10.2 (corresponding to $204 \mathrm{nM}$ ) after passing time of 100 (corresponding to $10 \mathrm{hr}$ ), where it reaches steady state at this value. At $K_{L 2}=25$ (corresponding to $500 \mathrm{nM}$ ), it is observed 


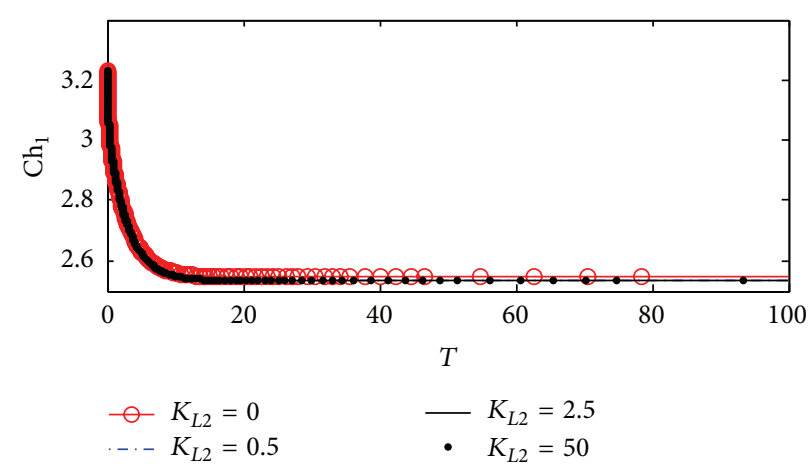

(a)

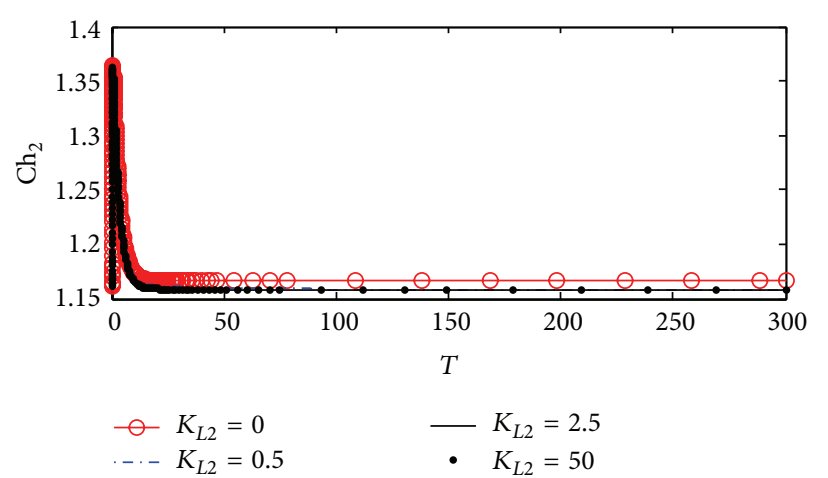

(b)

FIgURE 13: Time course of (a) choline concentration in compartment $1\left(\mathrm{Ch}_{1}\right)$ and (b) choline concentration in compartment $2\left(\mathrm{Ch}_{2}\right)$ at different $K_{L 2}$ values (according to kinetic mechanism 2).

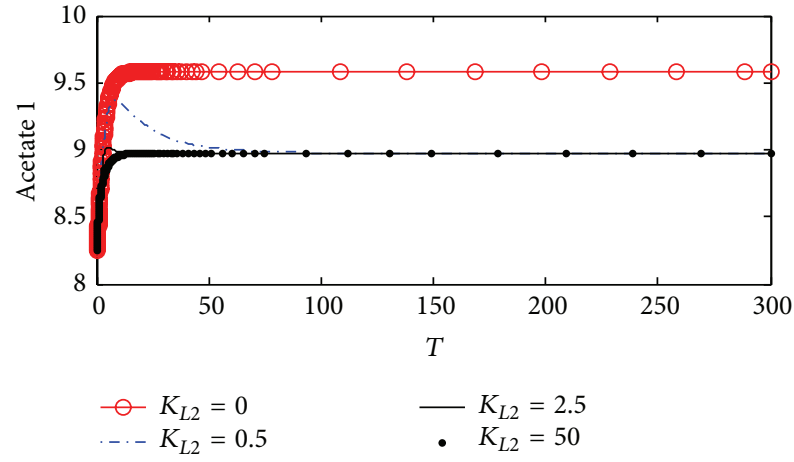

(a)

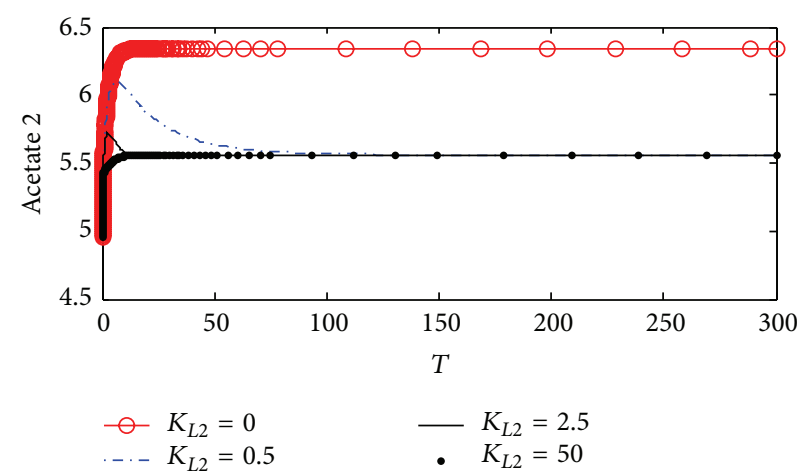

(b)

FIGURE 14: Time course according to kinetic mechanism 2 of (a) acetate concentration in compartment 1 (Ac $c_{1}$ ) and (b) acetate concentration in compartment $2\left(\mathrm{Ac}_{2}\right)$ at different $K_{L 2}$ values.

that $\beta$-amyloid aggregate oscillates in a narrow range $(10-$ $10.2)$ corresponding to $(200-204 \mathrm{nM})$. The oscillatory behavior is an interesting phenomenon because it may affect other state variables of the system as will be investigated below.

5.2.2. Rate of ACh Synthesis and Hydrolysis. Figure 18(a) shows the effect of varying inlet $\beta$-amyloid $K_{L 2}$ on ACh synthesis Rate 1 under the condition of ChAT fully inhibited according to (21). At normal ChAT synthesis where there is no $\beta$-amyloid aggregates generation, Rate 1 decreases from 0.014 at the beginning to 0.0105 which is the steady state value after passing time of 200 (corresponding to $20 \mathrm{hr}$ ). However, when $K_{L 2}$ increases to 0.5 and 25 (corresponding to 10 and $500 \mathrm{nM}$ ), Rate 1 decreases from 0.014 at the beginning of $\beta$ amyloid aggregates incubation to reach a very small value close to zero indicating that ChAT activity is completely inhibited by $\beta$-amyloid aggregates which attack every species in ChAT enzyme. It is observed that the reduction in Rate 1 decreases from 0.0105 to 0.000125 which refers to a reduction in ChAT activity of $99.7 \%$ with increasing $K_{L 2}$ from 0 to 25 (corresponding to $500 \mathrm{nM}$ ). This result is consistent with the experimental results obtained by Nunes-Tavares et al. [10] who showed that $\beta$-amyloid could inhibit ChAT completely.
Figure 18(b) shows that a very interesting phenomenon which is the oscillatory behavior at a high inlet $\beta$-amyloid aggregates $K_{L 2}=25$ where Rate 2 oscillates in the range (0.05-0.32) This oscillatory behavior reflects the disturbances occurring in the cholinergic system at which $\beta$-amyloid aggregates are generated at a high rate as shown in Figure 17 and acts severely as an inhibitor ChAT.

\subsubsection{ACh Concentrations in Compartments 1 and 2 .} Figure 19(a) shows that $\mathrm{ACh}_{1}$ is synthesized with a high rate at $K_{L 2}=0$ where $\mathrm{ACh}_{1}$ settles down to around 35 (corresponding to $219 \mu \mathrm{M}$ ) at the end of the time $T=200$ (corresponding to $30 \mathrm{hr}$ ). When $K_{L 2}=0.5$ (corresponding to $10 \mathrm{nM}$ ), the levels of $\mathrm{ACh}_{1}$ decrease to 2.7 (corresponding to $136 \mu \mathrm{M}$ ) after passing $T=100$ (corresponding to $10 \mathrm{hr}$ ); then $\mathrm{ACh}_{1}$ remains constant at the latter concentration until the end of the incubation period which is $30 \mathrm{hr}$. As $K_{L 2}$ increases to 25 (corresponding to $500 \mathrm{nM}$ ), the interesting oscillatory phenomenon appears where $\mathrm{ACh}_{1}$ oscillates in a wide range from 2.6 to 3.4 corresponding to $131-322 \mu \mathrm{M}$. This range shows that the $\mathrm{ACh}_{1}$ moves in disturbance and could be related to irregular behavior leading to impaired memory. Figure 19(b) shows that, at the highest value of $K_{L 2}=25$, 


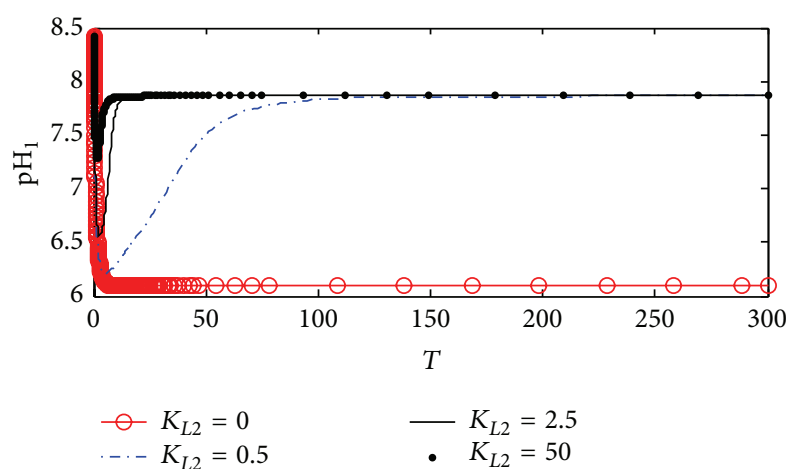

(a)

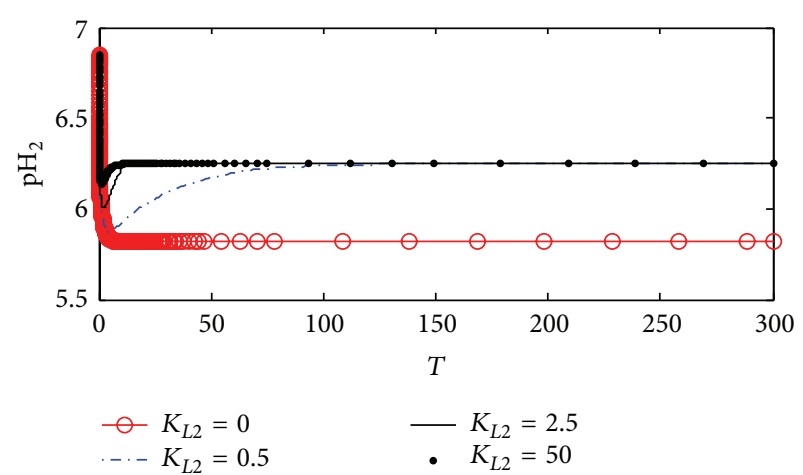

(b)

FIGURE 15: Time course according to kinetic mechanism 2 of (a) $\mathrm{pH}$ in compartment $1\left(\mathrm{pH}_{1}\right)$ and (b) $\mathrm{pH}$ in compartment 2 ( $\left.\mathrm{pH}_{2}\right)$ at different $K_{L 2}$ values.

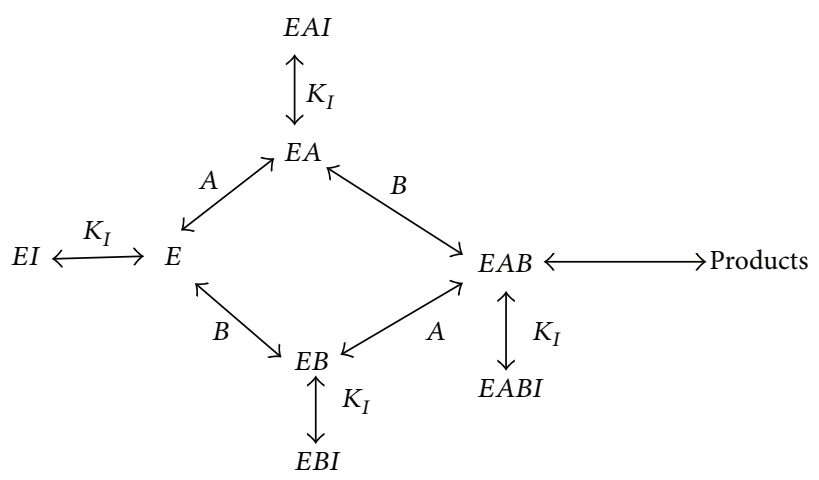

Figure 16: Possible noncompetitive inhibition mechanisms for $\beta$ amyloid aggregates during $\mathrm{pH}$-dependent ChAT synthesis of ACh: $\mathrm{E}=\mathrm{ChAT}, \mathrm{I}=\beta$-amyloid aggregates, $\mathrm{A}=$ choline, $\mathrm{B}=$ acetyl-coA, and Products $=$ ACh.

$\mathrm{ACh}_{2}$ fluctuates in a wide range (0.1-1.38) corresponding to $5-69.5 \mu \mathrm{M}$. The latter fluctuation shows the irregular behavior of $\mathrm{ACh}_{2}$ released in compartment 2 and could lead to unreasonable electrical and chemical messages to the postsynaptic receptors and finally dysfunctions of the memory. The latter disturbances show the harmful effect of high concentration $\beta$-amyloid aggregates and the consequences of inhibition action with all species in ChAT.

\subsubsection{Choline Concentrations in Compartments 1 and 2.} Figure 20(a) shows that there are no observable effects in the behavior of $\mathrm{Ch}_{1}$. This reflects that there is no effect of ChAT inhibition by $\beta$-amyloid aggregates on intracellular choline concentration indicating that both choline uptake and choline transport between compartments 1 and 2 are able to keep balanced intracellular choline concentration. It is observed that $\mathrm{Ch}_{1}$ decreases from 3.22 (corresponding to $322 \mu \mathrm{M}$ ) at the beginning of incubation to 2.55 (corresponding to $255 \mu \mathrm{M}$ ). Figure 20(b) shows a limited effect of varying $K_{L 2}$ on $\mathrm{Ch}_{2}$. $\mathrm{Ch}_{2}$ increases very fast at the beginning of the reaction from 1.15 (corresponding to $115 \mu \mathrm{M}$ ) to 1.36

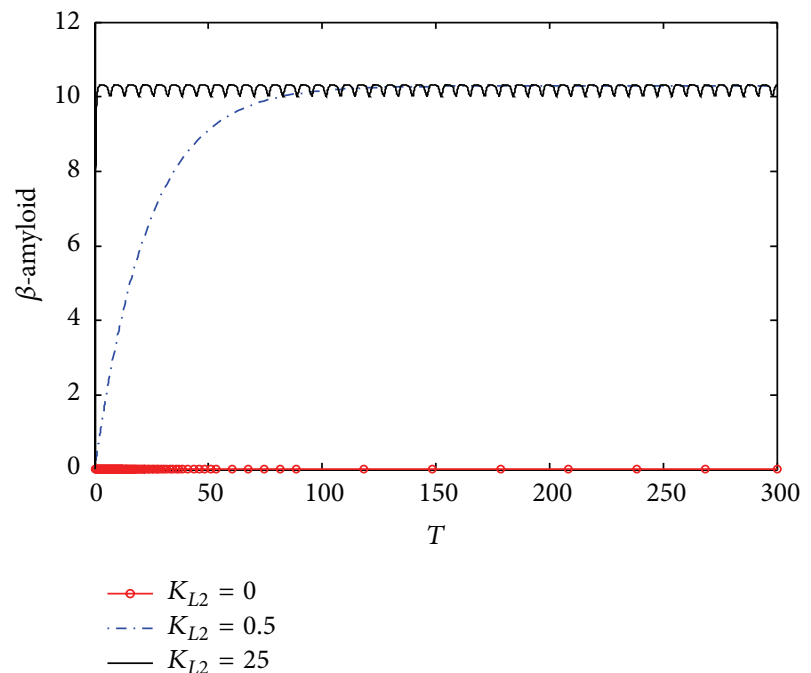

FIGURE 17: Time course of $\beta$-amyloid at different $K_{L 2}$ (according to kinetic mechanism 3).

(corresponding to $136 \mu \mathrm{M}$ ) in just a short time $T=0$ 2 corresponding to $0-0.2 \mathrm{hr}$ and then decreases to settle down at 1.16. Figure 21(a) shows that $\mathrm{Ch}_{1}$ decreases from 3.2 (corresponding to $320 \mu \mathrm{M}$ ) to 2.52 (corresponding to $252 \mu \mathrm{M}$ ) after passing $T=20$ (corresponding to $2 \mathrm{hr}$ ). Figures 22(a) and 22(b) are enlargement of Figures 20(a) and 20(b) where it is observed that $\mathrm{Ch}_{1}$ oscillates in a narrow range (2.532-2.538) (corresponding to $253.2-2538 \mu \mathrm{M}$ ) at $K_{L 2}=$ 25 (corresponding to $500 \mathrm{nM}$ ) as shown in Figure 22(a). Figure 22(b) shows that $\mathrm{Ch}_{2}$ oscillates through a limited range of 1.1548-1.1558 (corresponding to $115.48-155.8 \mu \mathrm{M}$ ).

The limited effect of $\mathrm{A} \beta$ aggregates inhibition on $\mathrm{Ch}_{1}$ and $\mathrm{Ch}_{2}$ is found to be negligible within the time frame studied. One likely explanation is that the choline uptake and the rate of ACh hydrolysis are all much larger in magnitude compared to that of ACh. While they all have an indirect dependence on the activity of ChAT through changes in $\mathrm{ACh}_{1}$ concentration, the reduction in $\mathrm{ACh}$ is too small to produce a significant effect on the concentrations of these components. 


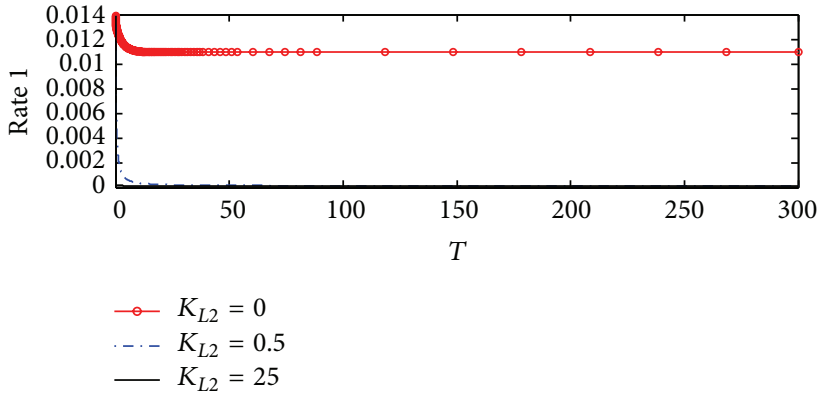

(a)

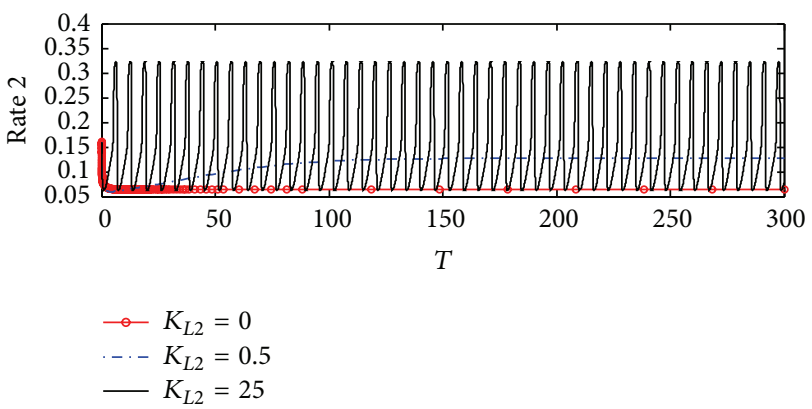

(b)

Figure 18: Time course of (a) rate of ACh synthesis (Rate 1) and (b) rate of ACh hydrolysis (Rate 2) at different $K_{L 2}$ (according to kinetic mechanism 3).

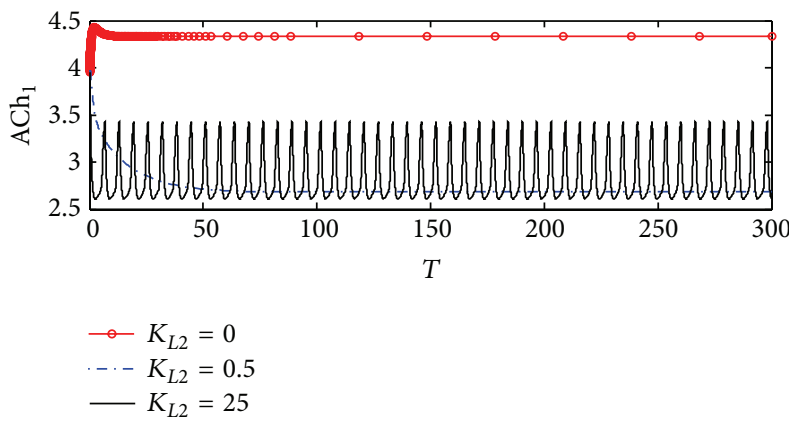

(a)

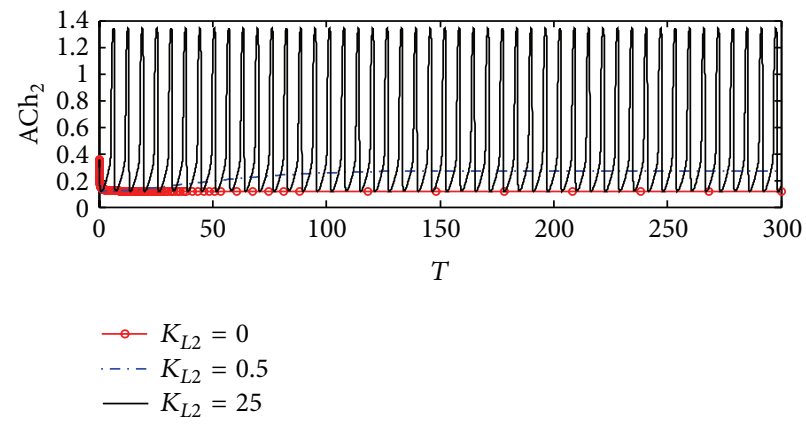

(b)

FIGURE 19: Time course of (a) ACh concentration in compartment $1\left(\mathrm{ACh}_{1}\right)$ and (b) $\mathrm{ACh}$ concentration in compartment $2(\mathrm{ACh})$ at different $K_{L 2}$ values (according to kinetic mechanism 3).

5.2.5. Acetate Concentrations in Compartments 1 and 2. Figure 23(a) shows the dynamic behaviors of acetate 1 at different $K_{L 2}$ values. It is observed that, at $K_{L 2}=0$ where no $\beta$-amyloid aggregates are produced, acetate 1 increases to settle down at the stationery state value of 9.6 (corresponding to $6.6 \mu \mathrm{M}$ ). As $K_{L 2}$ increases to 0.5 (corresponding to $10 \mathrm{nM}$ ), acetate 1 settles down at a lower value of 9.45 (corresponding to $9.45 \mu \mathrm{M}$ ). When $K_{L 2}$ increases to the highest value of 25 (corresponding to $500 \mathrm{nM}$ ), acetate 1 fluctuates in the range of 9-9.5 (corresponding to 9-9.5 $\mu \mathrm{M}$ ).

Figure 23(b) shows that acetate 2 , at $K_{L 2}=0$, takes steady state behavior which is around 6.4 (corresponding to $6.4 \mu \mathrm{M}$ ). While $K_{L 2}$ increases to 0.5 (corresponding to $10 \mathrm{nM}$ ), acetate 2 deceases to settle down around 5.6 (corresponding to $5.6 \mu \mathrm{M}$ ) which is lower than that at no inhibition $\left(K_{L 2}=0\right)$. When $K_{L 2}$ increases to 25 (corresponding to $500 \mathrm{nM}$ ), the oscillatory behavior dominates the system where acetate 2 fluctuates in the range $5-5.63$ corresponding to $5-5.63 \mu \mathrm{M}$.

5.2.6. $p H$ in Compartments 1 and 2. Figure 24(a) shows the dynamic response of $\mathrm{pH}_{1}$ at different $K_{L 2}$ values. It is observed that, at $K_{L 2}=0$ where no $\beta$-amyloid aggregate is produced, $\mathrm{pH}_{1}$ decreases rapidly from 8.5 to settle down at 6.2. At $K_{L 2}=0.5, \mathrm{pH}_{1}$ decreases from 8.5 to 6.75 in the period $0-5$ corresponding to $0-0.5 \mathrm{hr}$; then it increases to settle down around 8.4 which is the steady state value.
When $K_{L 2}$ increases to the high value of 25 (corresponding to $500 \mathrm{nM}), \mathrm{pH}_{1}$ oscillates in the range of 7.8-8.6.

Figure 24(b) shows that, at $K_{L 2}=0, \mathrm{pH}_{2}$ settles down around 5.8; when $K_{L 2}$ increases to 0.5 (corresponding to $10 \mathrm{nM}$ ), $\mathrm{pH}_{2}$ decreases from 6.65 to 6.1 in the period $0-5$ corresponding to $0-0.5 \mathrm{hr}$; then it increases to settle down around the steady state value of 6.8. It is observed that, at $K_{L 2}=25, \mathrm{pH}_{2}$ fluctuates in a wide range of 6.35-8.2 causing disturbances to the cholinergic system.

\section{Discussion}

The effect of $\beta$-amyloid aggregates inhibition on ChAT activity is investigated through proposing three different kinetic mechanisms. The first kinetic mechanism is that $\beta$ amyloid aggregate binds to active enzyme complex $\mathrm{E}_{2} \mathrm{H}$ in ChAT for producing ACh while in the second kinetic mechanism $\beta$-amyloid aggregates competitively bind to enzyme intermediate $\mathrm{X}_{2}$. In the third kinetic mechanism, $\beta$-amyloid aggregate binds all species in ChAT enzyme. In each kinetic mechanism, a rate equation of ACh synthesis $\left(r_{1}\right)$ is derived and incorporated into the two-enzyme/two-compartment model to get a cholinergic system with nine first-order ordinary differential equations. The concentrations of all state variables in compartments 1 and 2 in addition to the rates of $\mathrm{ACh}$ synthesis and $\mathrm{ACh}$ hydrolysis are investigated at 


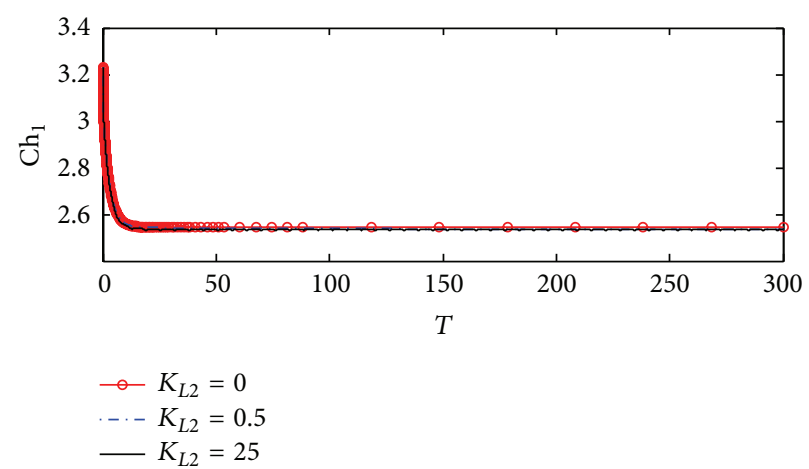

(a)

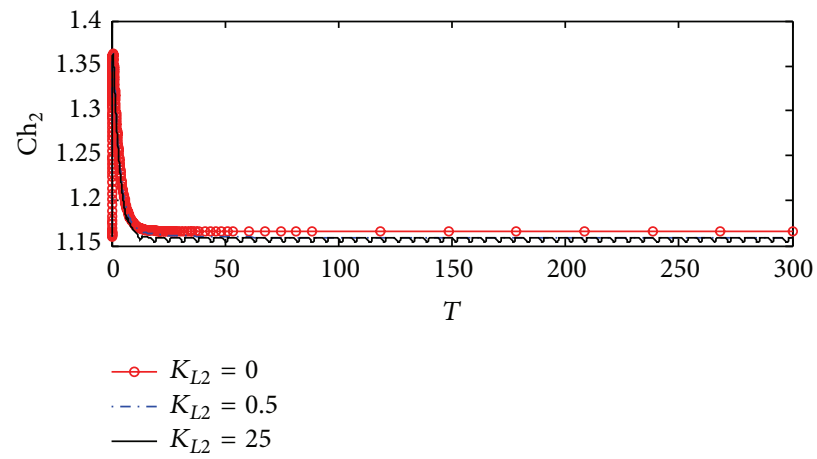

(b)

Figure 20: Time course of (a) choline concentration in compartment $1\left(\mathrm{Ch}_{1}\right)$ and (b) choline concentration in compartment $2\left(\mathrm{Ch}_{2}\right)$ at different $K_{L 2}$ values (according to kinetic mechanism 3).

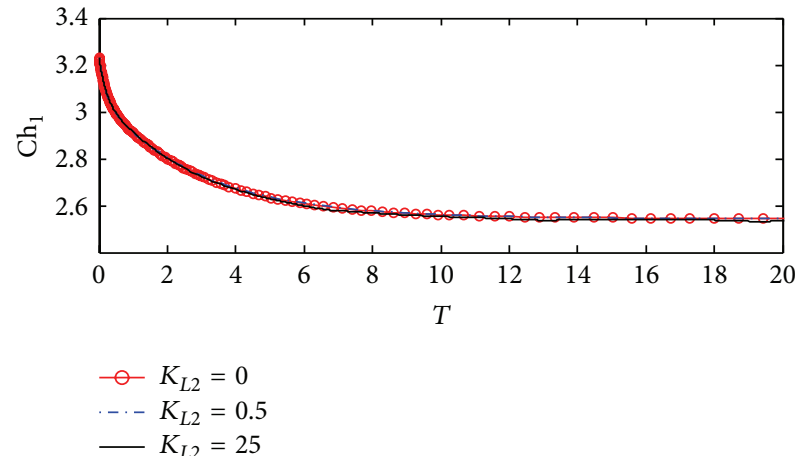

(a)

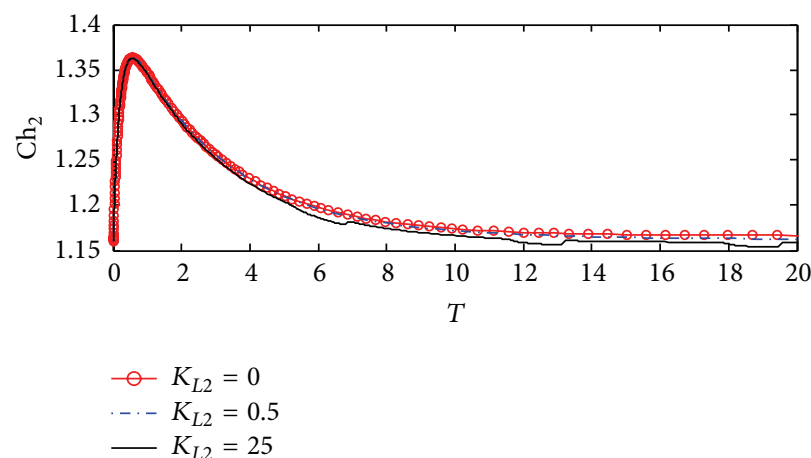

(b)

Figure 21: Magnification of Figure 20: (a) choline concentration in compartment $1\left(\mathrm{Ch}_{1}\right)$ and (b) choline concentration in compartment 2 $\left(\mathrm{Ch}_{2}\right)$ at different $K_{L 2}$ values (according to kinetic mechanism 3).

different rates of $\beta$-amyloid aggregates generation $\left(K_{L 2}\right)$ and compared with normal cholinergic neurons where there is no inhibition with $\beta$-amyloid aggregates.

It is found that for all kinetic mechanisms the concentration of generated $\beta$-amyloid aggregates increases with increasing $\beta$-amyloid aggregates production until it reaches saturation levels where there is no further increase with any additional increase of $K_{L 2}$. In the first kinetic mechanism where $\beta$-amyloid aggregate attacks only the active enzyme complex $\mathrm{E}_{2} \mathrm{H}$ in ChAT, it is found that the rate of $\mathrm{ACh}$ synthesis and the concentration of intracellular $\mathrm{ACh}\left(\mathrm{ACh}_{1}\right)$ decrease significantly with an increase in $K_{L 2}$ referring to the inhibition effect of ChAT activity while all of the other rates of $\mathrm{ACh}$ hydrolysis are not affected. In addition, $\mathrm{ACh}$ concentration in compartment $2\left(\mathrm{ACh}_{2}\right)$, choline concentrations in compartments, $\mathrm{pH}$ in both compartments, and acetate concentrations in both compartments are not affected by any change in $K_{L 2}$. Therefore, the interaction between $\beta$-amyloid aggregates and enzyme complex $\mathrm{E}_{2} \mathrm{H}$ in ChAT has a limited effect on most of elements of ACh neurocycle. One of the main explanations is that the limited effect of $\beta$ amyloid aggregates on substrates such as choline and acetylCoA in kinetic mechanism 1 is because of the idea that supply of these substrates such as choline from compartment 2 to compartment 1 and choline transport from compartment 1 to compartment 2 and acetate transport from compartment 1 to compartment 2 can compensate any reduction due to the inhibiting effect of $\beta$-amyloid aggregates on the active site $\mathrm{E}_{2} \mathrm{H}$. However, the significant reduction in ACh concentrations due to ChAT activity inhibition is one of the hallmarks in cholinergic dysfunctions.

The results of the second kinetic mechanism where $\beta$ amyloid aggregates competitively attack the enzyme intermediate $\mathrm{X}_{2}$ are similar to that of the first kinetic mechanism except that acetate concentration in compartments 1 and 2 decreases significantly while $\mathrm{pH}_{1}$ and $\mathrm{pH}_{2}$ in both compartments increase with the increase in $K_{L 2}$ where the attack of $\beta$-amyloid aggregates on intermediate $\mathrm{X}_{2}$ of ChAT leads to a decrease in the consumption of acetyl-CoA in compartment 1 and the lower production of acetate in compartment 2 . The reduction in Rate 1 or ChAT activity in kinetic mechanisms 1 and 2 decreases with around $25 \%$ with increase in $K_{L 2}$ from 0 to 25 (corresponding to $500 \mathrm{nM}$ ).

In the third kinetic mechanism, where $\beta$-amyloid aggregates bind to all species in ChAT, it is found that, at low values of $K_{L 2}$, the behavior of cholinergic ACh looks like that of the second kinetic mechanism. However, at high values of $K_{L 2}$ (e.g., 25), an interesting phenomenon arises for all state 

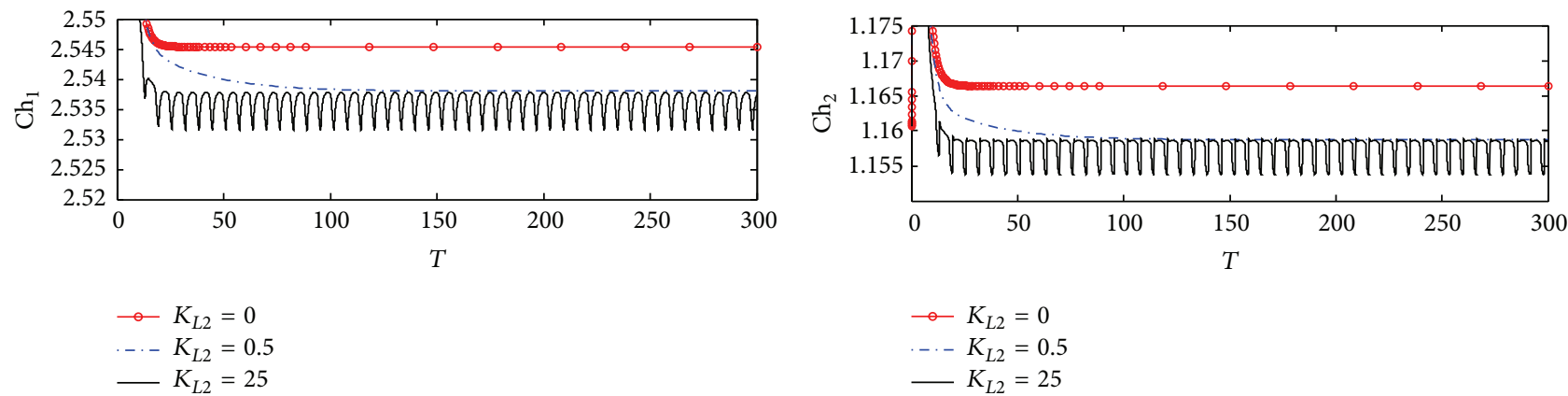

(a)

(b)

FIGURE 22: Magnification of Figure 20: (a) choline concentration in compartment $1\left(\mathrm{Ch}_{1}\right)$ and (b) choline concentration in compartment 2 $\left(\mathrm{Ch}_{2}\right)$ at different $K_{L 2}$ values (according to kinetic mechanism 3).

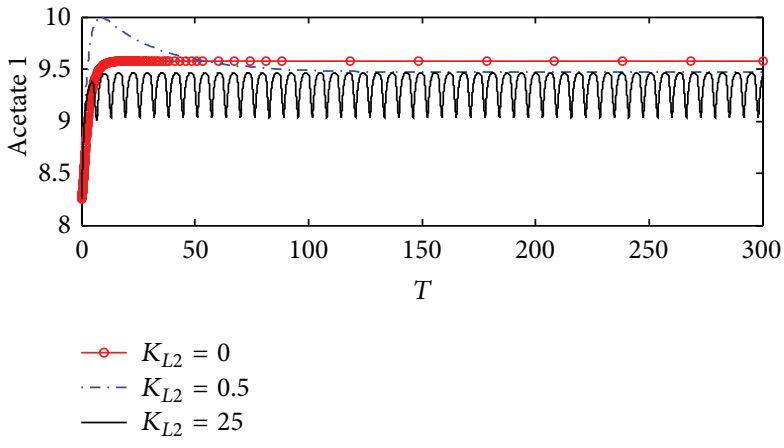

(a)

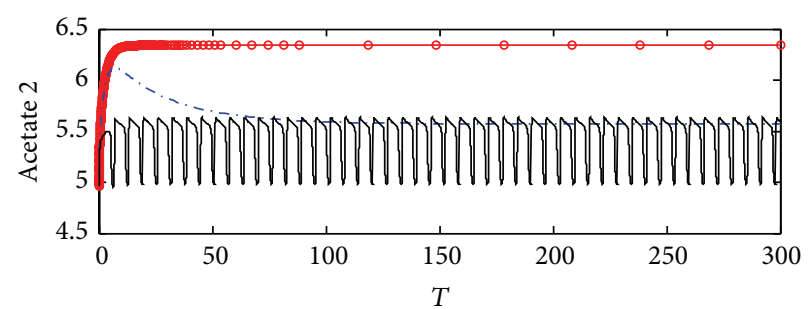

$$
\begin{aligned}
-K_{L 2} & =0 \\
--K_{L 2} & =0.5 \\
-K_{L 2} & =25
\end{aligned}
$$

(b)

FIGURE 23: Time course of (a) acetate concentration in compartment $1\left(\mathrm{Ac}_{1}\right)$ and $(\mathrm{b})$ acetate concentration in compartment $2\left(\mathrm{Ac}_{2}\right)$ at different $K_{L 2}$ values (according to kinetic mechanism 3).

variables of the system where all variables fluctuate in a wide range (as shown from Figures 17 to 22) leading to irregular behavior of the cholinergic system. These disturbances occurring in the cholinergic system are one of the main features of $\mathrm{AD}[10]$. According to kinetic mechanism 3, $\beta$-amyloid aggregates promote a major reduction in ChAT activity. Kar et al. [23] indicated that decline of intracellular ACh concentration is due to reduction in ChAT catalytic action. Moreover, it was observed that long incubation of rat primary septal culture neurons with micromolar concentration of $\beta$ amyloid aggregates caused a reduction in ChAT function and cell death $[23,42]$.

The results of kinetic mechanism 3 are compatible with the experimental results obtained by Nunes-Tavares et al. [10] who showed that $\beta$-amyloid aggregates could bind to a significant portion of cholinergic neurons and reduce ChAT activity completely. It is observed that the reduction in Rate 1 in kinetic mechanism 3 decreases from 0.0105 to 0.000125 which refers to a reduction in ChAT activity of $99.7 \%$ with increasing $K_{L 2}$ from 0 to 25 (corresponding to $500 \mathrm{nM}$ ). The results are in agreement with the experimental results obtained by Nunes-Tavares et al. [10] who showed that $\beta$ amyloid could inhibit ChAT completely.

It is observed that, after time of 100 (corresponding to $10 \mathrm{hr}$ ), there is no effect for any further change of $\beta$-amyloid aggregates production rate ( $K_{L 2}$ from 0.5 to 25 ), where all state variables reach the same steady state values. These results are compatible with those obtained by Nunes-Tavares et al. [10] who showed that there is no significant effect for any further $\beta$-amyloid concentration higher than $100 \mathrm{nM}$. It is also observed that ChAT inhibition by $\beta$-amyloid could cause severe consequences for the rate of ACh synthesis and ACh concentrations in compartments 1 and 2 as well, where ChAT inhibition could reach $100 \%$ as shown in Figure 18(a).

\section{Summary and Conclusions}

In this work, the effect of $\beta$-amyloid aggregates as an inhibitor on ChAT activity for ACh synthesis through the two-enzyme/two-compartment (2E2C) model in a variety of situations is analyzed through suggesting three different kinetic mechanisms for the inhibition effect. Overall, numerical solutions to the modified $2 \mathrm{E} 2 \mathrm{C}$ with $\beta$-amyloid aggregates were in accordance with three significant, widely reported symptoms of AD: loss of ChAT activity [20], reduced choline uptake [39], and reduced ACh production [20]. This in turn means that the direct inactivation of ChAT by $\beta$-amyloid aggregates may be a probable mechanism contributing to the development of AD. The incorporation of ChAT inhibition by $\beta$-amyloid aggregates into the $2 \mathrm{E} 2 \mathrm{C}$ model is able to 


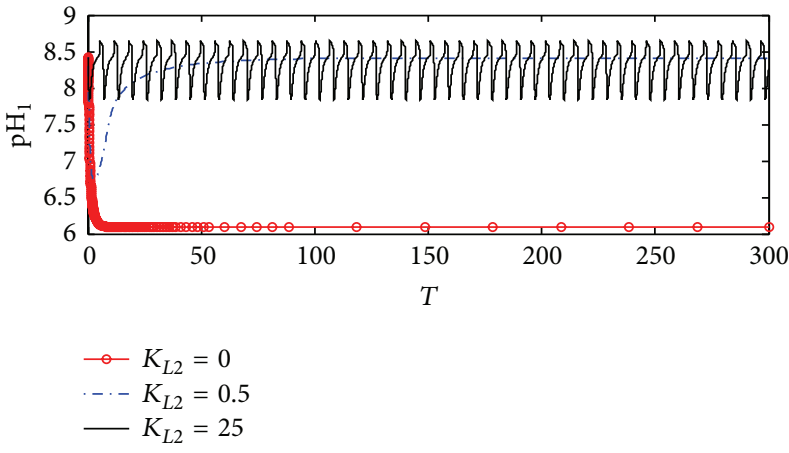

(a)

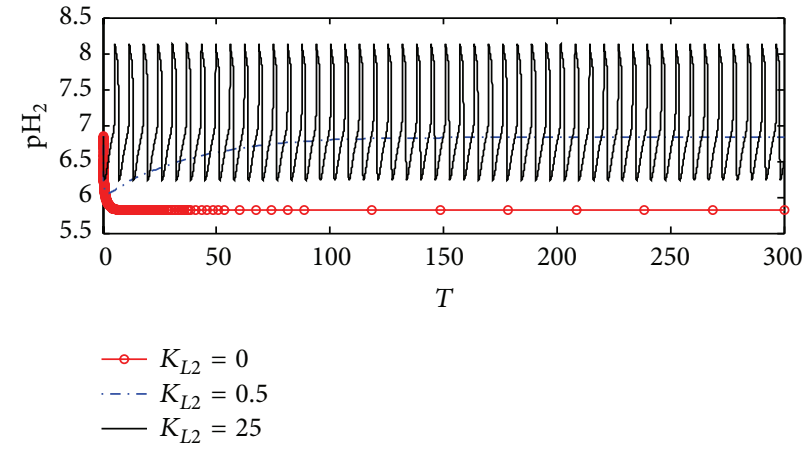

(b)

Figure 24: Time course of (a) $\mathrm{pH}$ in compartment $1\left(\mathrm{pH}_{1}\right)$ and (b) $\mathrm{pH}$ in compartment $2\left(\mathrm{pH}_{2}\right)$ at different $K_{L 2}$ values (according to kinetic mechanism 3).

yield dynamic solutions for concentrations of generated $\beta$ amyloid aggregates, $\mathrm{ACh}$, choline, acetate, and $\mathrm{pH}$ in addition to the rates of ACh synthesis and ACh hydrolysis in compartments 1 and 2 . This correlates well with the physiological understanding since the production of $\beta$-amyloid is not generally known to be highly reversible. One of the most significant physiological symptoms of $\mathrm{AD}$ is the reduction of ACh neurotransmitter concentration within cholinergic neurons. In this investigation, the effect of ChAT activity inhibition via $\beta$-amyloid is considered an individual basis in order to evaluate the validity of each kinetic mechanism, since it is highly likely that physiologically more than one single mechanism can contribute to the generation of AD symptoms. In comparison to the effect of $\beta$-amyloid via choline leakage hypothesis made by Ehrenstein et al. [28], it is observed that ChAT activity needs a high concentration of $\beta$-amyloid production rate $\left(K_{L 2}\right)$. This is in agreement with the experimental results obtained by Kar et al. [39] who showed that the exposure to small concentrations of $\beta$-amyloid aggregates has no impact on ChAT activity in cortex tissues. However, the results are in agreement with those obtained by Zambrzycka et al. [9] who showed that when neurons tissues are exposed to high concentrations of $\beta$-amyloid for a while, ChAT activity is reduced significantly. The results of kinetic mechanism 3 are in agreement with that obtained by Mustafa et al. [43, 44] who indicated the oscillatory behavior of ACh neurocycle at low ChAT activity.

\section{Dimensionless State Variables, Parameters, and Other} Terms $[5,6]$

Dimensionless State Variables

$s_{1(j)}=\left[S_{1}\right]_{(j)} / K_{s 1}$ : dimensionless ACh concentration in compartment $j$.

$s_{2(j)}=\left[S_{2}\right]_{(j)} /\left[S_{2}\right]_{\mathrm{ref}}$ : dimensionless choline concentration in compartment $j$.

$s_{3(j)}=\left[S_{3}\right]_{(j)} /\left[S_{3}\right]_{\mathrm{ref}}$ : dimensionless acetate concentration in compartment $j$.

$h_{(j)}=\left[\mathrm{H}^{+}\right]_{(j)} / K_{h 1}$ : dimensionless hydrogen ion concentration in compartment $j$.
Dimensionless Membrane Permeabilities

$$
\begin{aligned}
& \alpha_{A}=\alpha_{A}^{\prime} A_{M} / q . \\
& \alpha_{\mathrm{AC}}=\alpha_{\mathrm{AC}}^{\prime} A_{M} / q . \\
& \alpha_{S_{1}}=\alpha_{S_{1}}^{\prime} A_{M} / q . \\
& \alpha_{S_{3}}=\alpha_{S_{3}}^{\prime} A_{M} / q . \\
& \alpha_{S_{2}}=\alpha_{S_{2}}^{\prime} A_{M} / q . \\
& \alpha_{\mathrm{H}^{+}}=\alpha_{\mathrm{H}^{+}}^{\prime} A_{M} / q . \\
& \alpha_{\mathrm{OH}^{-}}=\alpha_{\mathrm{OH}^{-}}^{\prime} A_{M} / q .
\end{aligned}
$$

Other Terms Used in Dimensionless Form

$$
\begin{aligned}
& V_{R}=V_{(1)} / V_{(2)} . \\
& \gamma_{1}=K_{W} / K_{i 1} . \\
& T=q t / V_{(1)} . \\
& B_{1}=V_{1} V_{M 1} \overline{\mathrm{ChAT}} / q . \\
& B_{2}=V_{2} V_{M 2} \overline{\mathrm{AChE}} / q .
\end{aligned}
$$

\section{Notations}

$\mathrm{E}_{\mathrm{N}}: \quad$ Enzyme $\mathrm{N}$

$\mathrm{S}_{\mathrm{N}}$ : $\quad$ Substrate $\mathrm{N}$ (catalyzed by enzyme $\mathrm{N}$ )

$\mathrm{P}_{\mathrm{N}}$ : Reaction product $\mathrm{N}$ (produced by $\mathrm{S}_{\mathrm{N}}$ catalyzed by $\mathrm{E}_{\mathrm{N}}$ )

$\left[\mathrm{H}^{+}\right]$: Hydrogen ions concentration $\left(\mathrm{kmol} / \mathrm{m}^{3}\right)$

$\left[\mathrm{OH}^{-}\right]$: Hydroxyl ions concentration $\left(\mathrm{kmol} / \mathrm{m}^{3}\right)$

$\left[S_{1}\right]$ : Acetylcholine concentration $\left(\mathrm{kmol} / \mathrm{m}^{3}\right)$

$\left[S_{2}\right]$ : Choline concentration $\left(\mathrm{kmol} / \mathrm{m}^{3}\right)$

$\left[S_{3}\right]$ : Acetyl-CoA concentration $\left(\mathrm{kmol} / \mathrm{m}^{3}\right)$

$[a]$ : Acetate concentration $\left(\mathrm{kmol} / \mathrm{m}^{3}\right)$

AChE: Concentration of acetylcholinesterase enzyme in compartment 2 (kg enzyme $/ \mathrm{m}^{3}$ ) 


\begin{tabular}{|c|c|}
\hline$\overline{\text { hAT: }}$ & $\begin{array}{l}\text { Concentration of choline acetyltransferase i } \\
\text { compartment } 1\left(\mathrm{~kg} \text { enzyme } / \mathrm{m}^{3}\right)\end{array}$ \\
\hline$K_{s 1}, K_{i 1}, K_{h 1}:$ & $\begin{array}{l}\text { Kinetic constants for the choline } \\
\text { acetyltransferase catalyzed reaction } \\
\left(\mathrm{kmol} / \mathrm{m}^{3}\right)\end{array}$ \\
\hline$K_{s 2}, K_{i 2}, K_{h 2}:$ & $\begin{array}{l}\text { Kinetic constants for the coenzyme A } \\
\text { catalyzed reaction }\left(\mathrm{kmol} / \mathrm{m}^{3}\right)\end{array}$ \\
\hline$K_{s 3}:$ & $\begin{array}{l}\text { Kinetic constants for the acetylcholinesteras } \\
\text { catalyzed reaction }\left(\mathrm{kmol} / \mathrm{m}^{3}\right)\end{array}$ \\
\hline$A_{M}:$ & $\begin{array}{l}\text { Area of membrane separating compartments } \\
1 \text { and } 2\left(\mathrm{~m}^{2}\right)\end{array}$ \\
\hline$q:$ & $\begin{array}{l}\text { Volumetric flow rate into compartment } 1 \\
\left(\mathrm{~m}^{3} / \mathrm{s}\right)\end{array}$ \\
\hline$R_{W(j)}:$ & $\begin{array}{l}\text { Rate of water formation in compartment } j \\
\left(\mathrm{kmol} / \mathrm{m}^{3} \mathrm{~s}\right), j=1 \text { and } 2\end{array}$ \\
\hline$r_{(j)}:$ & $\begin{array}{l}\text { Rate of reaction in compartment } j \\
\left(\mathrm{kmol} / \mathrm{m}^{3} \mathrm{~s}\right), j=1,2 \text {, and } 3\end{array}$ \\
\hline$R:$ & Recycle flow rate ratio \\
\hline$V_{(j)}$ : & Volume of compartment $j\left(\mathrm{~m}^{3}\right), j=1$ and \\
\hline & Time $(\mathrm{s})$ \\
\hline$\alpha_{\mathrm{H}^{+}}^{\prime}:$ & $\begin{array}{l}\text { Membrane permeability for hydrogen ions } \\
(\mathrm{m} / \mathrm{s})\end{array}$ \\
\hline$\alpha_{\mathrm{OH}^{-}}^{\prime}:$ & $\begin{array}{l}\text { Membrane permeability for hydroxyl ions } \\
(\mathrm{m} / \mathrm{s})\end{array}$ \\
\hline$\alpha_{S_{1}}^{\prime}$ & $\begin{array}{l}\text { Membrane permeability for acetylcholine } \\
(\mathrm{m} / \mathrm{s})\end{array}$ \\
\hline $\mathrm{CS}_{2}$ & Membrane permeability for choline $(\mathrm{m} / \mathrm{s})$ \\
\hline$\alpha_{S_{3}}^{\prime^{2}}:$ & $\begin{array}{l}\text { Membrane permeability for acetyl-CoA } \\
(\mathrm{m} / \mathrm{s})\end{array}$ \\
\hline$\alpha_{a}^{\prime}:$ & Membrane permeability for acetate $(\mathrm{m} / \mathrm{s})$ \\
\hline & Membrane permeability for acetic acid $(\mathrm{m}$ \\
\hline$K_{W}:$ & Equilibrium constant for water $\left(\mathrm{kmol}^{2} / \mathrm{m}^{6}\right.$ \\
\hline
\end{tabular}

Abbreviations

AChE: Acetylcholinesterase

ChAT: Choline acetyltransferase

CoA: Coenzyme A

ACh: Acetylcholine

AC: Acetate

CSTR: Continuous stirred tank reactor.

\section{Subscripts}

1: Compartment 1

2: Compartment 2

$f$ : Feed condition.

\section{Conflict of Interests}

The authors declare that there is no conflict of interests regarding the publication of this paper.

\section{References}

[1] K. S. Lips, J. Wunsch, S. Zarghooni et al., "Acetylcholine and molecular components of its synthesis and release machinery in the urothelium," European Urology, vol. 51, no. 4, pp. 10421053, 2007.

[2] D. Nachmansohn and A. L. Machado, "The formation of acetylcholine. A new enzyme choline acetylase," Journal of Neurophysiology, vol. 6, pp. 397-403, 1943.

[3] Y. Oda, "Choline acetyltransferase: the structure, distribution and pathologic changes in the central nervous system," Pathology International, vol. 49, no. 11, pp. 921-937, 1999.

[4] Y. Abreu-Villaça, C. C. Filgueiras, and A. C. Manhães, "Developmental aspects of the cholinergic system," Behavioural Brain Research, vol. 221, no. 2, pp. 367-378, 2011.

[5] I. H. Mustafa, G. Ibrahim, A. Elkamel, S. S. E. H. Elnashaie, and P. Chen, "Non-linear feedback modeling and bifurcation of the acetylcholine neurocycle and its relation to Alzheimer's and Parkinson's diseases," Chemical Engineering Science, vol. 64, no. 1, pp. 69-90, 2009.

[6] I. H. Mustafa, A. Elkamel, G. Ibrahim, P. Chen, and S. S. E. H. Elnashaie, "Effect of choline and acetate substrates on bifurcation and chaotic behavior of acetylcholine neurocycle and Alzheimer's and Parkinson's diseases," Chemical Engineering Science, vol. 64, no. 9, pp. 2096-2112, 2009.

[7] N. N. Tavares and A. Hassón-Voloch, "Choline acetyltransferase from the electric organ of Electrophorus electricus (L.) physicochemical characterization and immunochemical identification," Zeitschrift fur Naturforschung, vol. 53, no. 5-6, pp. 407415, 1998.

[8] E. P. Brandon, T. Mellott, D. P. Pizzo et al., "Choline transporter 1 maintains cholinergic function in choline acetyltransferase haploinsufficiency," The Journal of Neuroscience, vol. 24, no. 24, pp. 5459-5466, 2004.

[9] A. Zambrzycka, M. Alberghina, and J. B. Strosznajder, "Effects of aging and amyloid- $\beta$ peptides on choline acetyltransferase activity in rat brain," Neurochemical Research, vol. 27, no. 4, pp. 277-281, 2002.

[10] N. Nunes-Tavares, L. E. Santos, B. Stutz et al., "Inhibition of choline acetyltransferase as a mechanism for cholinergic dysfunction induced by amyloid- $\beta$ peptide oligomers," The Journal of Biological Chemistry, vol. 287, no. 23, pp. 19377-19385, 2012.

[11] N. Nunes-Tavares, N. L. Cunha-E-Silva, and A. Hassón-Voloch, "Choline acetyltransferase detection in normal and denervated electrocyte from Electrophorus electricus (L.) using a confocal scanning optical microscopy analysis," Anais da Academia Brasileira de Ciências, vol. 72, no. 3, pp. 331-340, 2000.

[12] A. J. Raeber, G. Riggio, and P. G. Waser, "Purification and isolation of choline acetyltransferase from the electric organ of Torpedo marmorata by affinity chromatography," European Journal of Biochemistry, vol. 186, no. 3, pp. 487-492, 1989.

[13] S. Tucek, "Regulation of acetylcholine synthesis in the brain," The Journal of Neurochemistry, vol. 44, no. 1, pp. 11-24, 1985.

[14] I. H. Mustafa, A. Elkamel, G. Ibrahim, S. S. E. H. Elnashaie, and A. Lohi, "Effect of feed substrate concentrations on dynamic performance of bioethanol fermentation process using Zymomonas mobilis," Energy \& Fuels, vol. 28, no. 8, pp. 55435556, 2014.

[15] I. H. Mustafa, A. Elkamel, A. Lohi, G. Ibrahim, and S. S. E. H. Elnashaie, "Structured mathematical modeling, bifurcation, and simulation for the bioethanol fermentation process using Zymomonas mobilis," Industrial and Engineering Chemistry Research, vol. 53, no. 14, pp. 5954-5972, 2014.

[16] D. L. Craft, L. M. Wein, and D. J. Selkoe, "A mathematical model of the impact of novel treatments on the $A \beta$ burden in the 
Alzheimer's brain, CSF and plasma," Bulletin of Mathematical Biology, vol. 64, no. 5, pp. 1011-1031, 2002.

[17] B. V. Zlokovic, J. Ghiso, J. B. Mackie, J. G. McComb, M. H. Weiss, and B. Frangione, "Blood-brain barrier transport of circulating Alzheimer's amyloid $\beta$," Biochemical and Biophysical Research Communications, vol. 197, no. 3, pp. 1034-1040, 1993.

[18] C. L. Martel, J. B. Mackic, J. G. McComb, J. Ghiso, and B. V. Zlokovic, "Blood-brain barrier uptake of the 40 and 42 amino acid sequences of circulating Alzheimer's amyloid $\beta$ in guinea pigs," Neuroscience Letters, vol. 206, no. 2-3, pp. 157-160, 1996.

[19] A. Nitta, A. Itoh, T. Hasegawa, and T. Nabeshima, " $\beta$-Amyloid protein-induced Alzheimer's disease animal model," Neuroscience Letters, vol. 170, no. 1, pp. 63-66, 1994.

[20] W. A. Pedersen and J. K. Blusztajn, "Characterization of the acetylcholine-reducing effect of the amyloid- $\beta$ peptide in mouse SN56 cells," Neuroscience Letters, vol. 239, no. 2-3, pp. 77-80, 1997.

[21] D. D. Allen, Z. Galdzicki, S. K. Brining, R. Fukuyama, S. I. Rapoport, and Q. R. Smith, "Beta-amyloid induced increase in choline flux across PC12 cell membranes," Neuroscience Letters, vol. 234, no. 1, pp. 71-73, 1997.

[22] Z. Galdzicki, R. Fukuyama, K. C. Wadhwani, S. I. Rapoport, and G. Ehrenstein, "Beta-amyloid increases choline conductance of PC12 cells: possible mechanism of toxicity in Alzheimer's disease," Brain Research, vol. 646, no. 2, pp. 332-336, 1994.

[23] S. Kar, S. P. M. Slowikowski, D. Westaway, and H. T. J. Mount, "Interactions between $\beta$-amyloid and central cholinergic neurons: implications for Alzheimer's disease," Journal of Psychiatry and Neuroscience, vol. 29, no. 6, pp. 427-441, 2004.

[24] K. Duff and F. Suleman, "Transgenic mouse models of Alzheimer's disease: how useful have they been for therapeutic development?" Briefings in Functional Genomics \&; Proteomics, vol. 3, no. 1, pp. 47-59, 2004.

[25] Y. Lu, "Integrating experimentation and quantitative modeling to enhance discovery of beta amyloid lowering therapeutics for Alzheimer's disease," Frontiers in Pharmacology, vol. 3, article 177, 2012.

[26] Y. Lu, L. Zhang, C. E. Nolan et al., "Quantitative pharmacokinetic/pharmacodynamic analyses suggest that the 129/SVE mouse is a suitable preclinical pharmacology model for identifying small-molecule gamma-secretase inhibitors," Journal of Pharmacology and Experimental Therapeutics, vol. 339, no. 3, pp. 922-934, 2011.

[27] J. D. Buxbaum, A. A. Ruefli, C. A. Parker, A. M. Cypess, and P. Greengard, "Calcium regulates processing of the Alzheimer amyloid protein precursor in a protein kinase C-independent manner," Proceedings of the National Academy of Sciences of the United States of America, vol. 91, no. 10, pp. 4489-4493, 1994.

[28] G. Ehrenstein, Z. Galdzicki, and G. D. Lange, "The cholineleakage hypothesis for the loss of acetylcholine in Alzheimer's disease," Biophysical Journal, vol. 73, no. 3, pp. 1276-1280, 1997.

[29] L. B. Hersh and M. Peet, "Re-evaluation of the kinetic mechanism of the choline acetyltransferase reaction," The Journal of Biological Chemistry, vol. 252, no. 14, pp. 4796-4802, 1977.

[30] P. Garhyan, A. Mahecha-Botero, and S. S. E. H. Elnashaie, "Complex bifurcation/chaotic behavior of acetylcholinesterase and cholineacetyltransferase enzymes system," Applied Mathematical Modelling, vol. 30, no. 9, pp. 824-853, 2006.

[31] G. Ibrahim and S. S. E. H. Elnashaie, "Hyperchaos in acetylcholinesterase enzyme systems," Chaos, Solitons \& Fractals, vol. 8, no. 12, pp. 1977-2007, 1997.
[32] S. S. E. H. Elnashaie, M. A. El-Rifai, and G. Ibrahim, "The effect of hydrogen ion production on the steady-state multiplicity of substrate inhibited enzymatic reactions. II. Transient behavior," Applied Biochemistry and Biotechnology, vol. 8, p. 467, 1983.

[33] S. S. E. H. Elnashaie, M. A. El-Rifai, and G. Ibrahim, "The effect of hydrogen ions on the steady state multiplicity of substrateinhibited enzymatic reactions. III. Asymmetrical steady-states in enzyme membranes," Applied Biochemistry and Biotechnology, vol. 9, no. 5-6, pp. 455-474, 1984.

[34] S. S. E. H. Elnashaie, G. Ibrahim, and F. A. Teymour, "Chaotic behaviour of an acetylcholinesterase enzyme system," Chaos, Solitons \& Fractals, vol. 5, no. 6, pp. 933-954, 1995.

[35] C. A. Guyton and J. E. Hall, Textbook of Medical Physiology, W.B. Saunders Company, Amsterdam, The Netherlands, 10th edition, 2000.

[36] S. Tucek, Acetylcholine Synthesis in Neurons, Chapman \& Hall, London, UK, 1978.

[37] S. Tucek, "The synthesis of acetylcholine," in Handbook of Neurochemistry, A. Lajtha, Ed., vol. 4, pp. 219-249, Plenum Press, New York, NY, USA, 2nd edition, 1983.

[38] I. López-Coviella, B. Berse, R. Krauss, R. S. Thies, and J. K. Blusztajn, "Induction and maintenance of the neuronal cholinergic phenotype in the central nervous system by BMP-9," Science, vol. 289, no. 5477, pp. 313-316, 2000.

[39] S. Kar, A. M. Issa, D. Seto, D. S. Auld, B. Collier, and R. Quirion, "Amylod $\beta$-peptide inhibits high-affinity choline uptake and acetylcholine release in rat hippocampal slices," The Journal Neurochemistry, vol. 70, no. 5, pp. 2179-2187, 1998.

[40] W.-H. Zheng, S. Bastianetto, F. Mennicken, W. Ma, and S. Kar, "Amyloid $\beta$ peptide induces tau phosphorylation and loss of cholinergic neurons in rat primary septal cultures," Neuroscience, vol. 115, no. 1, pp. 201-211, 2002.

[41] C. Yung-Chi and W. H. Prusoff, "Relationship between the inhibition constant $\left(K_{I}\right)$ and the concentration of inhibitor which causes 50 per cent inhibition $\left(I_{50}\right)$ of an enzymatic reaction," Biochemical Pharmacology, vol. 22, no. 23, pp. 30993108, 1973.

[42] O. F. Olesen, L. Dagø, and J. D. Mikkelsen, "Amyloid $\beta$ neurotoxicity in the cholinergic but not in the serotonergic phenotype of RN46A cells," Molecular Brain Research, vol. 57, no. 2, pp. 266-274, 1998.

[43] I. Mustafa, A. Elkamel, A. Lohi, P. Chen, S. S. E. H. Elnashaie, and G. Ibrahim, "Application of continuation method and bifurcation for the acetylcholine neurocycle considering partial dissociation of acetic acid," Computers and Chemical Engineering, vol. 46, pp. 78-93, 2012.

[44] I. H. Mustafa, G. Ibrahim, A. Elkamel, S. S. E. H. Elnashaie, and P. Chen, "Effect of cholineacetyltransferase activity and choline recycle ratio on diffusion-reaction modeling, bifurcation and chaotic behavior of acetylcholine neurocycle and their relation to Alzheimer's and Parkinson's diseases," Chemical Engineering Science, vol. 68, no. 1, pp. 19-35, 2012. 


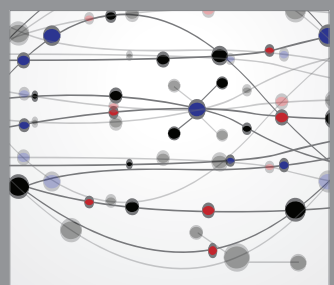

The Scientific World Journal
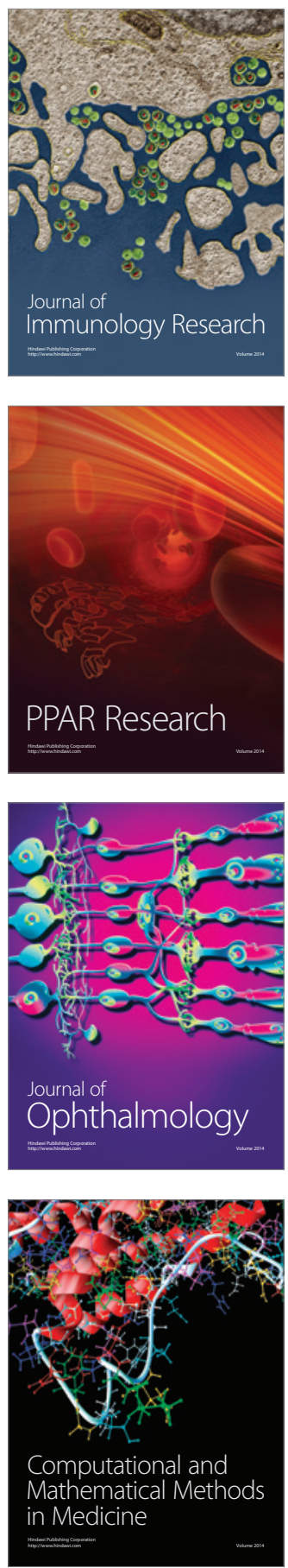

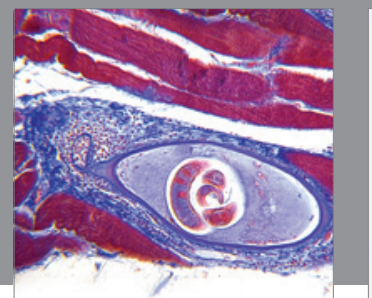

Gastroenterology

Research and Practice
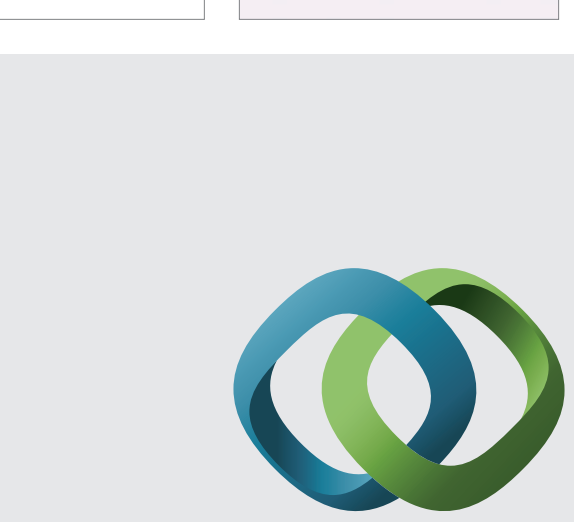

\section{Hindawi}

Submit your manuscripts at

http://www.hindawi.com
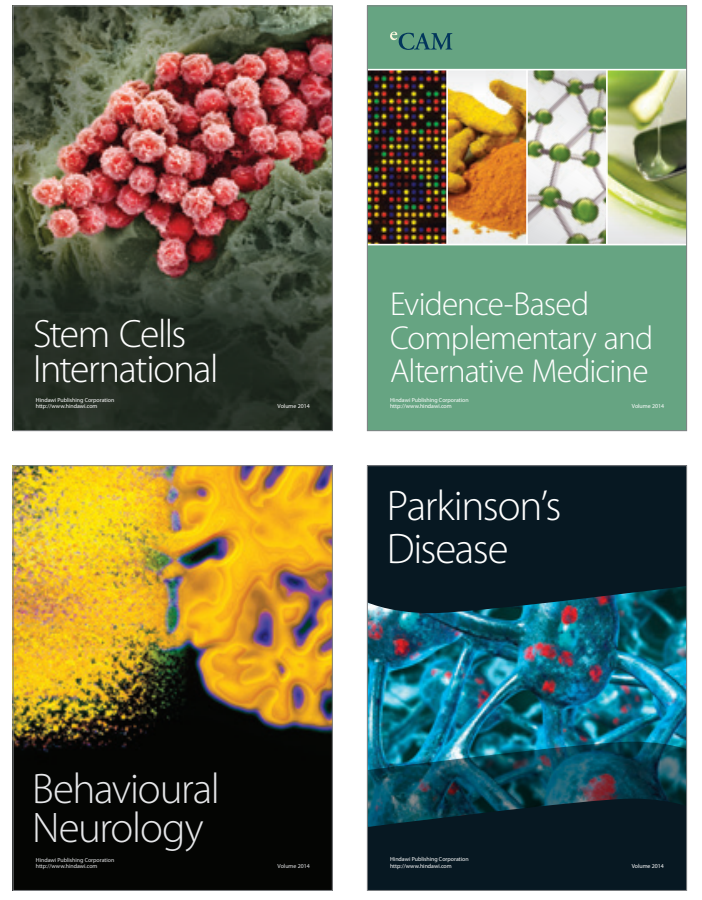
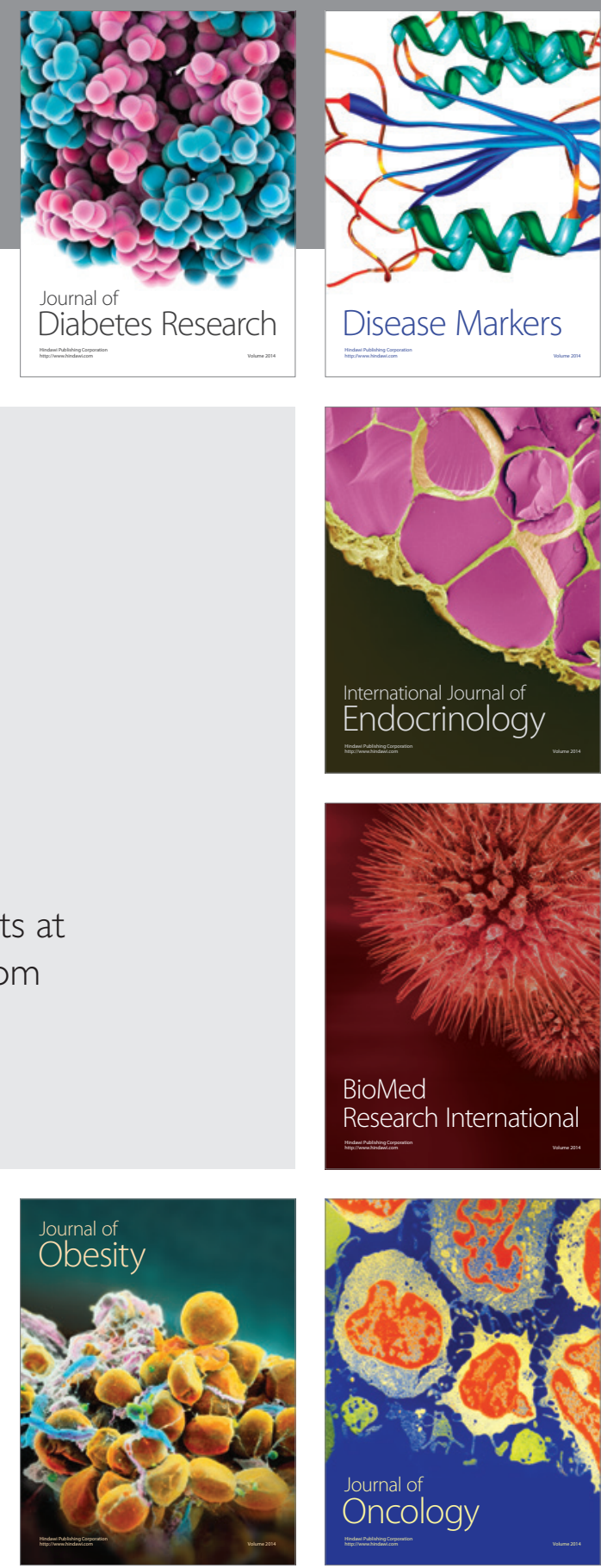

Disease Markers
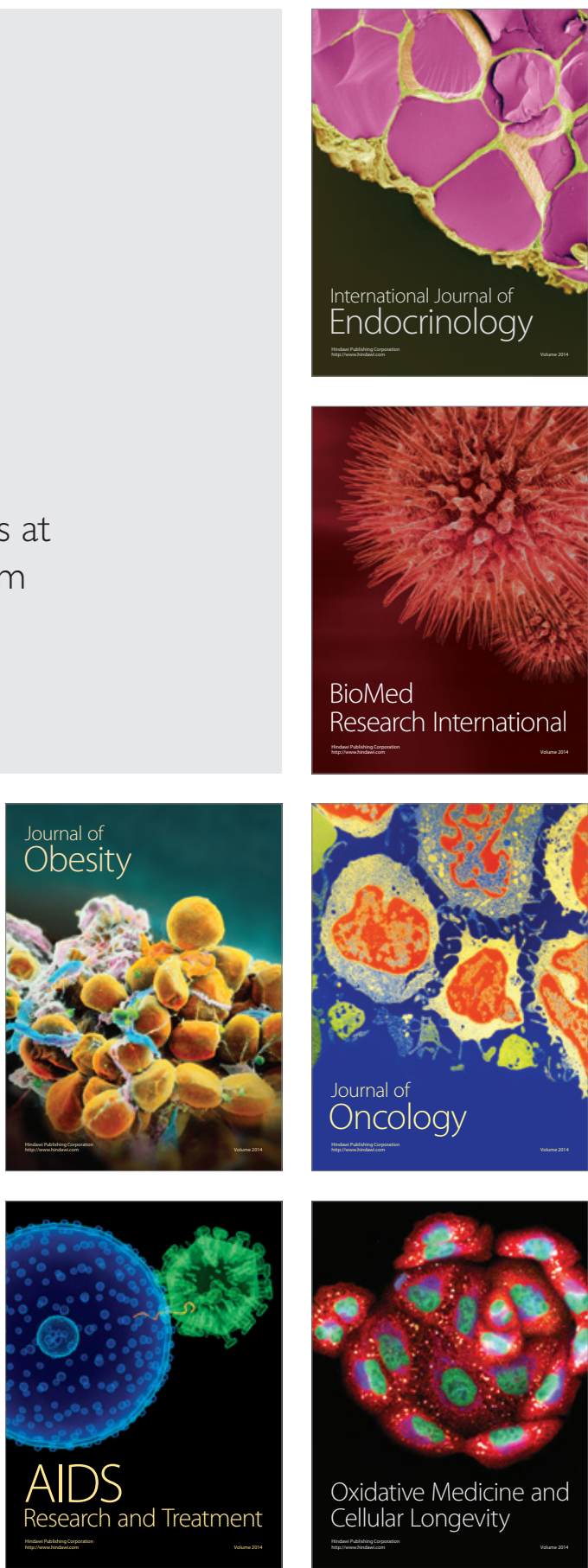